Old Dominion University

ODU Digital Commons

CCPO Publications

Center for Coastal Physical Oceanography

2006

\title{
Population Dynamics Model of the Hard Clam, Mercenaria Mercenaria: Development of the Age- and Length-Frequency Structure of the Population
}

Eileen E. Hofmann

Old Dominion University, ehofmann@odu.edu

John M. Klinck

Old Dominion University, jklinck@odu.edu

John N. Kraeuter

Eric N. Powell

Follow this and additional works at: https://digitalcommons.odu.edu/ccpo_pubs

\section{Repository Citation}

Hofmann, Eileen E.; Klinck, John M.; Kraeuter, John N.; and Powell, Eric N., "Population Dynamics Model of the Hard Clam, Mercenaria Mercenaria: Development of the Age- and Length-Frequency Structure of the Population" (2006). CCPO Publications. 36. https://digitalcommons.odu.edu/ccpo_pubs/36 accepted for inclusion in CCPO Publications by an authorized administrator of ODU Digital Commons. For more information, please contact digitalcommons@odu.edu. 


\title{
A POPULATION DYNAMICS MODEL OF THE HARD CLAM, MERCENARIA MERCENARIA: DEVELOPMENT OF THE AGE- AND LENGTH-FREQUENCY STRUCTURE OF THE POPULATION
}

\author{
Author(s): EILEEN E. HOFMANN, JOHN M. KLINCK, JOHN N. KRAEUTER, ERIC N. POWELL, \\ RAY E. GRIZZLE, STUART C. BUCKNER, and V. MONICA BRICELJ \\ Source: Journal of Shellfish Research, 25(2):417-444. \\ Published By: National Shellfisheries Association \\ DOI: http://dx.doi.org/10.2983/0730-8000(2006)25[417:APDMOT]2.0.CO;2 \\ URL: http://www.bioone.org/doi/full/10.2983/0730-8000\%282006\%2925\%5B417\%3AAPDMOT \\ $\% 5 \mathrm{D} 2.0 . \mathrm{CO} \% 3 \mathrm{~B} 2$
}

BioOne (www.bioone.org) is a nonprofit, online aggregation of core research in the biological, ecological, and environmental sciences. BioOne provides a sustainable online platform for over 170 journals and books published by nonprofit societies, associations, museums, institutions, and presses.

Your use of this PDF, the BioOne Web site, and all posted and associated content indicates your acceptance of BioOne's Terms of Use, available at www.bioone.org/page/terms_of_use.

Usage of BioOne content is strictly limited to personal, educational, and non-commercial use. Commercial inquiries or rights and permissions requests should be directed to the individual publisher as copyright holder. 


\title{
A POPULATION DYNAMICS MODEL OF THE HARD CLAM, MERCENARIA MERCENARIA: DEVELOPMENT OF THE AGE- AND LENGTH-FREQUENCY STRUCTURE OF THE POPULATION
}

\author{
EILEEN E. HOFMANN, ${ }^{1 *}$ JOHN M. KLINCK, ${ }^{1}$ JOHN N. KRAEUTER, ${ }^{2}$ ERIC N. POWELL, ${ }^{2}$ \\ RAY E. GRIZZLE, ${ }^{3}$ STUART C. BUCKNER ${ }^{4}$ AND V. MONICA BRICELJ ${ }^{5}$ \\ ${ }^{1}$ Center for Coastal Physical Oceanography, Crittenton Hall, Old Dominion University, Norfolk, \\ Virginia 23529; ${ }^{2}$ Haskin Shellfish Research Laboratory, Rutgers University, 6959 Miller Ave., Port \\ Norris, New Jersey 08340; ${ }^{3}$ Jackson Estaurine Laboratory, 85 Adams Point Road, University of New \\ Hampshire, Durham, New Hampshire 03824; ${ }^{4}$ Town of Islip Environmental Control, 401 Main Street, \\ Islip, New York 11751; ${ }^{5}$ Institute for Marine Biosciences, National Research Council, 1411 Oxford \\ Street, Halifax, Nova Scotia, Canada, B3H $3 Z 1$
}

\begin{abstract}
An individual-based model was developed to simulate growth of the hard clam, Mercenaria mercenaria, in response to temperature, salinity and food supply conditions. Unique characteristics of the model are that: (1) length and tissue weight are related only by condition index, so that weight, up to a point, can vary independently of length, and (2) age is decoupled from length. Tissue weight changes result from the difference in assimilation and respiration. Changes in hard clam condition are determined from a standard length-weight relationship for average hard clam growth. Changes in hard clam length (growth) occur only when condition index is greater than zero, which happens when excess weight for a given length is attained. No change in length occurs if condition index is zero (mean case) or negative (less weight than expected at a given length). This model structure resolves limitations that accompany models used to simulate the growth and development of shellfish populations. The length-frequency distribution for a cohort was developed from the individual-based model through simulation of a suite of genotypes with varying physiological capabilities. Hard clam populations were then formed by the yearly concatenation of cohorts with partially independent trajectories that are produced by cohort- and population-based processes. Development and verification of the hard clam model was done using long-term data sets from Great South Bay, New York that have been collected by the Town of Islip, New York. The ability to separately track length and age in the simulations allowed derivation of a general mathematical relationship for describing age-length relationships in hard clam populations. The mathematical relationship, which is based on a twisted bivariate Gaussian distribution, reproduces the features of age-length distributions observed for hard clam populations. The parameters obtained from fitting the twisted bivariate Gaussian to simulated hard clam length-frequency distributions obtained for varying conditions yield insight into the growth and mortality processes and population-dependent processes, compensatory and otherwise, that structured the population. This in turn provides a basis for development of theoretical models of population age-length compositions. The twisted bivariate Gaussian also offers the possibility of rapidly and inexpensively developing age-length keys, used to convert length-based data to age-based data, by permitting a relatively few known age-length pairs to be expanded into the full age- and length-frequency structure of the population.
\end{abstract}

KEY WORDS: Mercenaria mercenaria, individual-based model, age-length structure, length-frequency distribution, age-frequency distribution

\section{INTRODUCTION}

Hard clam (Mercenaria mercenaria) populations in the bays along the south shore of Long Island, New York, have diminished since reaching peak abundance in the 1970s (Schlenk 2000). The definitive cause of this decline has not been demonstrated, but intensive harvesting may have initially reduced clam abundance (Buckner 1984, COSMA 1985) and experimental observations suggest that recent occurrences of the toxic picoplanktonic alga Aureococcus anophagefferens (brown tide, Pelagophyceae) may have impacted larval and juvenile survivorship (Bricelj 2000). Hard clam growth rates may have declined relative to past years (Cerrato 2000a), and the same factors slowing growth may have led to decreased gamete production.

During the 1990s other biological and environmental factors, such as temperature, salinity, phytoplankton species and/or concentrations, and predator abundance, may have changed as well. For example, during the $1990 \mathrm{~s}$, mean winter water temperature in the Long Island region was $1^{\circ} \mathrm{C}$ to $3^{\circ} \mathrm{C}$ warmer than the long-term average (Nixon et al. 2004). A significant predator, the blue crab

\footnotetext{
*Corresponding author. E-mail: hofmann@ccpo.odu.edu
}

(Callinectes sapidus), may have recently increased its population levels in this region. Hard clam abundance may have declined enough to adversely affect fecundity (Kraeuter et al. 2005). Thus, the observed reduction in hard clam abundance and the failure of the Great South Bay fishery to recover, despite a reduction in fishing pressure in recent years, likely result from multiple factors.

A mathematical model provides one approach for investigating the relative effect of the many potential factors affecting hard clam populations. The first objective of this study is then to develop a mathematical model that can simulate the growth and population dynamics of the hard clam in response to specified biological and environmental conditions. The model is implemented for Great South Bay, NY where long-term data sets on hard clam abundance and distribution, collected by the Town of Islip, NY, provide calibration and evaluation of the simulations.

An additional important consideration for the Great South Bay ecosystem is development of management strategies that allow rebuilding of the now depleted hard clam stocks. A reliable means for determining population age-length characteristics is an important aspect of developing management strategies because fisheries models, such as virtual population analysis models, depend on age-frequency information for the population (e.g., Hilborn \& Walters 1992, Patterson 1998, Clark 1999, Bradbury \& Tagart 
2000). The age structure of populations is also important in ecological research, as indicated by the many theoretical and empirical studies that relate age and lifespan to population processes (e.g., Bayne et al. 1983, Hoenig 1983, Connell \& Sousa 1983, Bayne et al. 1983, McNamara 1993, Lundberg \& Persson 1993, Nunney \& Elam 1994).

Population age is usually obtained from an age-length relationship that prescribes the likelihood that an individual of a given length will have a given age, the age-frequency at length, and conversely, the likelihood that an individual of a given age will have a given length, the length-frequency at age (e.g., Kimura 1977, Mohn 2001). For molluscs, aging typically relies on counting of yearly growth bands in shells (e.g., Cerrato 2000b, Goodwin et al. 2001, Richardson 2001) or statoliths (e.g., Lipinski et al. 1998, Richardson 2001). These methods are costly, time consuming, and technically difficult. As a consequence, most empirical studies do not measure the age distribution of all animals sampled from a population or compare age structures in multiple populations. This limits ecological research into the age-length structure of natural populations and the use of sophisticated age-dependent models in fisheries management.

Because of measurement limitations, information on age structure for multiple samples or assemblages typically relies on an age-length key to estimate age frequency from length frequency. Age-length keys can be as simple as mean age-mean length relationships for an individual cohort, normally obtained by fitting a growth model to empirical data (e.g., Tanabe 1988, Smith et al. 1997, Devillers et al. 1998, Millstein \& O’Clair 2001). Many factors affect the length frequency of a single cohort over time (e.g., Craig \& Oertel 1966). As a result, the age structure of a population derived from many cohorts may not necessarily match that of a single cohort or even a subset of cohorts and the population age and length structure determined using a cohort-based age-length key may not reflect the population as a whole.

Thus, a second goal of this study is to use the hard clam model, which simulates independently the age and length structure of the population, to investigate the age-length characteristics of a population that are produced by variations in environmental and biological processes. These simulations were used to derive a general mathematical function that describes the age-length relationship and its variations in hard clam populations. A general age-length relationship for hard clam populations provides an approach for inferring the processes that produced the population structure.

The hard clam population dynamics model is described in the next section. This is followed by an examination of simulations of hard clam growth and development for a range of environmental conditions and biological processes. Following this, the simulations that provide the basis for derivation of a hard clam age-length relationship are described and the mathematical formulation of the age-length relationship is given. The discussion section summarizes the results within the context of current understanding of hard clam populations.

\section{MODEL DESCRIPTION}

\section{Hard Clam Model Structure}

The hard clam model simulates a single individual with a particular physiology. The model structure is based on the assumption that changes in weight and length of an individual hard clam are related to the condition of the animal. This assumption is implemented by independently calculating hard clam weight and length over time. The weight obtained at any given time is compared with an average length-weight relationship that was derived for hard clams (described below). The difference between the simulated weight and that obtained from the average curve determines how "fit" the hard clam is at a given time. The length-weight-condition coordinate system allows shell growth to be defined as a function of animal condition rather than as a function of animal weight. Changes in condition dictate whether length can increase. Positive condition supports somatic or reproductive tissue growth and normally shell elongation. Neutral or negative condition does not. This approach ensures that hard clam weight and length remain only partially coupled during a simulation because weight can change without requiring a corresponding change in length. As a result, realistic length-weight combinations cannot be exceeded, but reductions in condition can occur seasonally, as is observed.

Changes in hard clam weight, condition and length are produced by the environmental and physiological processes that control the growth and reproduction of an individual animal (Fig. 1). Ambient temperature, salinity, and total concentration of suspended solids modify filtration rate, which determines food ingestion. Assimilation is determined by the assimilation efficiency and loss to respiration. The apportionment of the resulting net production into somatic and reproductive tissue is determined by temperature, hard clam weight and animal condition. Somatic tissue growth during times of positive clam condition results in an increase in hard clam shell length. Reproductive tissue is formed when net production and condition are positive and temperature is favorable for reproduction. Spawning occurs when the gamete fraction exceeds a threshold fraction of total animal weight. Periods of negative net production result in resorption of reproductive tissue to cover metabolic needs and eventually resorption of somatic tissue.

A cohort is created from the individual-based model by a set of independently-simulated individuals defined by a range of physiological and genetic capabilities (Fig. 2). The frequency of each

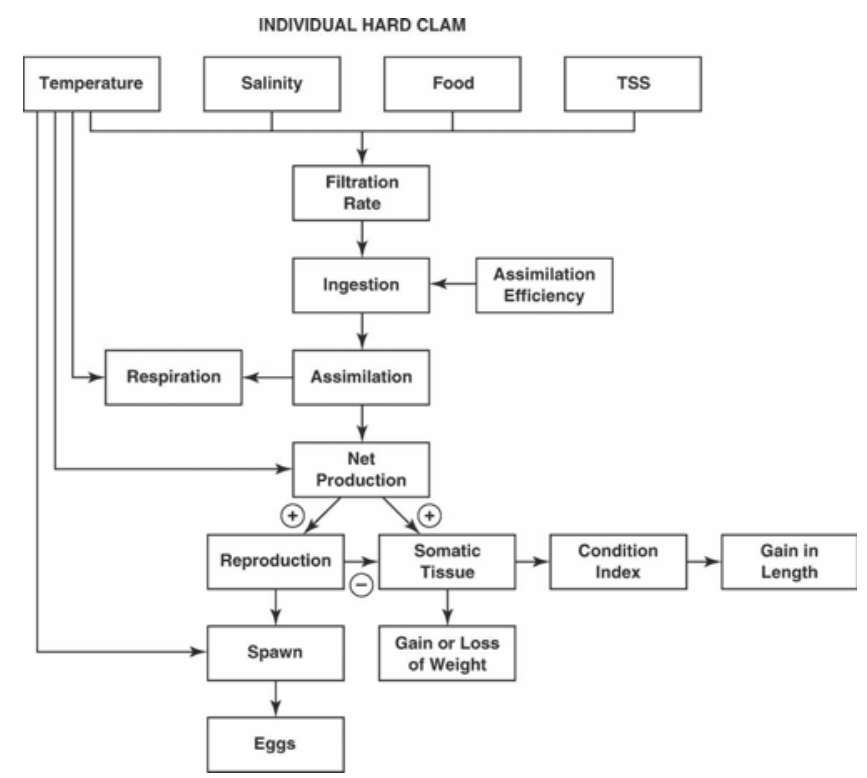

Figure 1. Schematic of the processes and transfers included in the individual-based hard clam model. Total suspended solids is abbreviated as TSS. The division of net production is determined by temperature, animal weight, and animal condition. Positive net production (+) results in formation of reproductive and somatic tissue. Negative net production (-) results in resorption of reproductive tissue. 


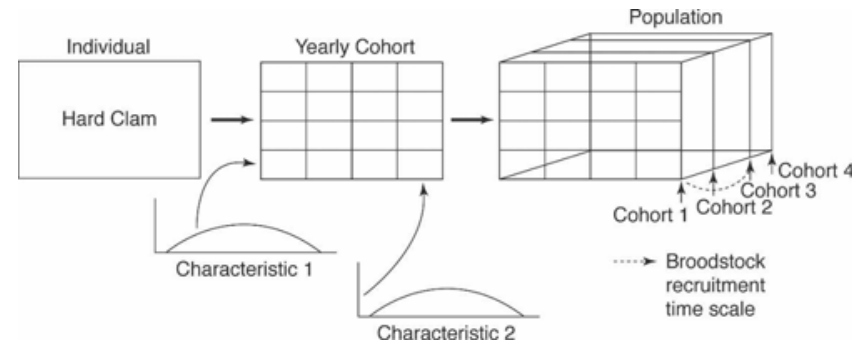

Figure 2. Schematic of the approach used to scale the results of the individual-based clam model to the cohort and population level. For the Great South Bay, NY reference simulation (Figures 10 and 11), characteristics 1 and 2 were the length of a 2-y-old hard clam and assimilation efficiency, respectively. See text for details.

genotype in the cohort is determined by a probability distribution, described below, so that the cohort is a weighted sum of the set of independently-simulated individual genotypes. Concatenations of cohorts over a period of years, as determined by a broodstockrecruitment relationship, builds a hard clam population much as a series of yearly recruitment events and subsequent growth does in the natural world (Fig. 2).

The governing equations used to calculate changes in hard clam weight, condition, and length are described in the following section. This is followed by descriptions of the parameterizations used to represent the physiological processes determining growth and reproduction of an individual hard clam. The final sections describe the approaches used to specify the cohort and population genetics and the broodstock-recruitment relationship used to form the population structure.

\section{Hard Clam Model Governing Equations}

\section{Weight Equation}

Changes in hard clam body weight ( $W$, mg dry wt) over time $(t)$ are based on net production, which is given by the difference in assimilation $(A)$ and respiration $(R)$ as:

$$
\frac{d W}{d t}=(A-R) W
$$

The weight change obtained from Eq. (1) is the primary input into the calculation of hard clam condition index, described in the next section. The parameterizations for assimilation and respiration for the individual-based hard clam model are described in subsequent sections and definitions and values of coefficients are given in Table 1.

\section{Condition Index Equation}

Hard clam condition index, $C(L, W)$, is defined as a ratio of the current weight, $W(t)$ obtained from Eq. (1), to a standard weight, $W_{0}(L)$, and a maximum weight, $W_{m}(L)$, of an individual hard clam as:

$$
C(L, W)=\frac{W(t)-W_{0}(L)}{W_{m}(L)-W_{0}(L)}
$$

where the standard and maximum clam weights are functions of clam length, $L(\mathrm{~mm})$. The condition index obtained from Eq. (2) indicates how fit a clam is at any given time for a specified set of environmental conditions. Positive condition index, when a clam has a mass for a given length that is above the standard value, ranges from $0-1$. Values less than zero occur when a clam has a mass for a given length below that obtained from the standard length-weight relationship.
The standard and maximum weights for individual hard clams as a function of clam length used in Eq. (2) are obtained from empirically-derived relationships. The weight and length observations for 30-120 mm hard clams given in Hibbert (1977) were used to develop an allometric equation. However, using this allometric equation for the standard length-weight relationship resulted in growth for 5-20 mm hard clams that was too rapid relative to observed growth rates for this size range. Examination of additional hard clam length and weight data (Kraeuter unpubl. data), that included 5-20 mm clams $(n=450)$, showed that small hard clams weigh more at a given length than is estimated from the Hibbert (1977) length-weight relationship. Combining the 5-20 mm hard clam data with the Hibbert (1977) data allowed a new average length-weight relationship to be obtained:

$$
W_{0}(L)=a_{0} L^{3}+b_{0} L^{2}+c_{0} L+d_{0} .
$$

The maximum weight attained for a given length is:

$$
W_{m}(L)=a_{m} L^{3}+b_{m} L^{2}+c_{m} L+d_{m} .
$$

This length-weight relationship (Fig. 3) allows for small hard clams that are heavier for a given length and large clams that are longer for a given weight than the values obtained from the relationship derived by Hibbert (1977). The implication is that small hard clams do not follow allometric growth. Implementing Eqs. (3) and (4) with the hard clam model resulted in simulated growth rates that gave lengths during the first five years of clam life that matched the hard clam age-length observations given in Wallace (1991).

The time-dependent variation in hard clam condition index (Eq. 2 ) is calculated from changes in weight (Eq. 1), the average and maximum length-weight relationships (Eqs. 3 and 4, respectively) and length (Eq. 6 in the next section) as:

$$
\begin{aligned}
\frac{d C(L, W)}{d t}= & \frac{1}{\left(W_{m}(L)-W_{0}(L)\right)^{2}}\left[\left(W_{m}(L)-W_{0}(L)\right)\left(\frac{d W}{d t}-\frac{d W_{0}}{d L} \frac{d L}{d t}\right)\right. \\
& \left.-\left(W(t)-W_{0}(L)\right)\left(\frac{d W_{m}}{d L}-\frac{d W_{0}}{d L}\right) \frac{d L}{d t}\right] .
\end{aligned}
$$

\section{Length Equation}

When excess weight for a given length relative to the average length-weight relationship (Eq. 3) occurs, a positive condition index, the excess weight produces an increase in shell length calculated as:

$$
\frac{d L}{d t}=g l(C) L \frac{L_{i n f}-L}{L_{i n f}}
$$

where $g l(C)$ is the rate of shell length increase and $L_{\text {inf }}$ sets a maximum hard clam length. The form of Eq. (6) results in incrementally smaller increases in shell length as the maximum length is approached.

The rate of shell length change is a function of hard clam condition and is assumed to follow a hyperbolic relationship:

$$
g l(C)=g l_{\max } \frac{C(L, W)}{g l k+C(L, W)}
$$

where $g l_{\text {max }}$ is the maximum specific rate of increase in length, $g l k$ is the condition index value at which hard clam length increments at one-half the value of the maximum rate, and condition, $C(L, W)$, is obtained from Eq. (2). The rate of shell increase is analogous to the parameter in the von Bertalanffy equation, which determines the rate of length increase $(k)$. As a result, observations and models 
TABLE 1.

Definitions, units, and values of parameters and coefficients used in the individual-based hard clam model.

\begin{tabular}{|c|c|c|c|}
\hline Coefficient & Definition & Units & Value \\
\hline$a_{0}$ & average weight constant & mg dry wt $(\mathrm{mm})^{-3}$ & $1.1373 \times 10^{-5}$ \\
\hline$b_{0}$ & average weight constant & mg dry wt $(\mathrm{mm})^{-2}$ & $-6.6545 \times 10^{-5}$ \\
\hline$c_{0}$ & average weight constant & mg dry wt $(\mathrm{mm})^{-1}$ & $1.4092 \times 10^{-3}$ \\
\hline$d_{0}$ & average weight constant & mg dry wt & -0.014814 \\
\hline$a_{m}$ & maximum weight constant & $\mathrm{mg}$ dry wt $(\mathrm{mm})^{-3}$ & $1.706 \times 10^{-5}$ \\
\hline$b_{m}$ & maximum weight constant & $\mathrm{mg}$ dry wt $(\mathrm{mm})^{-2}$ & $-9.9817 \times 10^{-5}$ \\
\hline$c_{m}$ & maximum weight constant & mg dry wt $(\mathrm{mm})^{-1}$ & $2.1139 \times 10^{-3}$ \\
\hline$d_{m}$ & maximum weight constant & mg dry wt & -0.02222 \\
\hline$L_{\text {inf }}$ & maximum length & $\mathrm{mm}$ & 150 \\
\hline$g l_{\max }$ & maximum specific rate of length increase & $\mathrm{d}^{-1}$ & 0.008 \\
\hline$g l k$ & $0.5 g l_{\max }$ & condition & 0.20 \\
\hline$f a$ & filtration rate dependence on length & none & 0.96 \\
\hline$f b$ & filtration rate dependence on temperature & none & 0.95 \\
\hline$f_{c}$ & constant & $\left(\mathrm{cm}{ }^{\circ} \mathrm{C}\right.$ ind $\left.\min \right) \mathrm{mL}^{-1}$ & 2.95 \\
\hline$f_{0}$ & filtration rate coefficient & none & 0.25 \\
\hline$T_{\text {Low }}$ & low temperature cut off for filtration & ${ }^{\circ} \mathrm{C}$ & 7.5 \\
\hline$T_{f}$ & temperature cut off for filtration & ${ }^{\circ} \mathrm{C}$ & 0.5 \\
\hline$T_{H i g h}$ & high temperature cut off for filtration & ${ }^{\circ} \mathrm{C}$ & 29.0 \\
\hline$f_{s 0}$ & salinity filtration constant & none & -4.302 \\
\hline$f_{\mathrm{s} 1}$ & salinity filtration & $\mathrm{ppt}^{-1}$ & 0.4144 \\
\hline$f_{s 2}$ & salinity filtration constant & $\mathrm{ppt}^{-2}$ & $-8.1027 \times 10^{-3}$ \\
\hline$a_{T S S}$ & total suspended solids filtration constant & $\mathrm{L}(\mathrm{g} \text { dry } w t)^{-1}$ & 1.225 \\
\hline$b_{T S S}$ & total suspended solids filtration constant & none & -0.375 \\
\hline$A E_{0}$ & base assimilation efficiency & none & 0.075 \\
\hline$A E_{1}$ & assimilation efficiency constant & none & 0.575 \\
\hline$A E_{k}$ & assimilation efficiency half saturation coefficient & mg dry wt & 0.8001 \\
\hline$a_{r}$ & base respiration rate & $\mu \mathrm{L} \mathrm{O}_{2}(\mathrm{~h} \text { g dry wt) })^{-1}$ & 52.1314 \\
\hline$b_{r}$ & respiration weight dependence & none & 0.8484 \\
\hline$c_{r}$ & respiration temperature dependence & $\left({ }^{\circ} \mathrm{C}\right)^{-1}$ & 0.1012 \\
\hline$T_{0}$ & base respiration temperature & ${ }^{\circ} \mathrm{C}$ & 20.0 \\
\hline$R_{1}$ & reproductive efficiency constant & $\left({ }^{\circ} \mathrm{C}\right)^{-1}$ & 1.5 \\
\hline$R_{0}$ & reproductive efficiency constant & none & 0.125 \\
\hline$S R_{0}$ & spawn ratio constant & none & 0.2 \\
\hline$S R_{1}$ & spawn ratio constant & mg dry wt & 3.0 \\
\hline$S R_{2}$ & spawn ratio constant & $(\mathrm{mg} \text { dry } w t)^{-1}$ & 0.0346 \\
\hline
\end{tabular}

of hard clam growth (Kennish \& Loveland 1980, Loesch \& Haven 1973) can be used as a guide for determining the parameters controlling the rate of shell growth in Eq. (7).

\section{Model Parameterizations}

\section{Filtration Rate}

Doering and Oviatt (1986) provide a relationship for hard clam filtration rate $(F R)$ as a function of clam length and temperature $(T)$ of the form:

$$
F R_{0}(L, T)=\frac{L^{f a} T^{f b}}{f c}
$$

that allows filtration rate to increase with increasing hard clam length and temperature.

Results from experiments designed to show the effect of temperature on hard clam filtration rate over a range of lengths (Hamwi 1969) indicate that filtration rate is maximal between $17^{\circ} \mathrm{C}$ and $25^{\circ} \mathrm{C}$, decreases at temperatures above and below these values, and ceases at $6^{\circ} \mathrm{C}$ and $32^{\circ} \mathrm{C}$. This pattern holds over a range of hard clam lengths. This temperature dependency was incorporated by modifying Eq. (8) as:

$$
\begin{aligned}
F R_{1}(L, T)= & F R_{0} f_{0}\left(1+\tanh \left(\frac{T-T_{\text {Low }}}{T f}\right)\right) \\
& \left(1-\tanh \left(\frac{T-T_{\text {High }}}{T_{f}}\right)\right)
\end{aligned}
$$

where the hyperbolic tangent function (tanh) provides the temperature dependency that is observed in the observations presented in Hamwi (1969). However, the use of Eq. (9) with an upper temperature limit $\left(T_{\mathrm{High}}\right)$ on maximal filtration rate of $25^{\circ} \mathrm{C}$ produced incorrect growth rates for simulations that used summer temperatures that exceeded this value. Setting the upper temperature limit for maximum filtration rate to $29^{\circ} \mathrm{C}$ (Fig. 4) gave correct growth rates for hard clams in environments where the summer maximum temperatures exceeded $25^{\circ} \mathrm{C}$. Some evidence for a higher temperature limit on filtration is provided by observations (Ansell 1968) that show hard clam growth up to $28-29^{\circ} \mathrm{C}$, which then decreases at higher temperatures. These limited observations and the simulation results obtained using Eq. (9) suggest that a latitudinal variation in the upper temperature limit for hard clam maximum filtration may exist. However, verification studies using environmental conditions from southern regions have not been done. Thus, the form of the filtration rate temperature dependency for temperatures exceeding those typical of Great South Bay is tentative. 


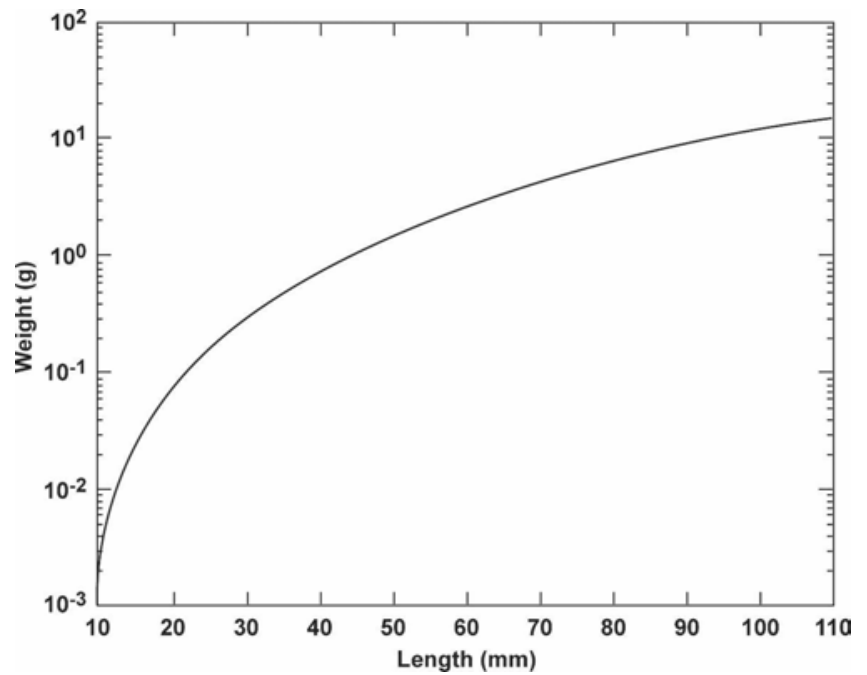

Figure 3. Standard hard clam length-weight relationship given by Eq. (3).

Additional experimental results show that hard clam filtration rate increases with increasing salinity (Hamwi 1969). This effect, described by a quadratic function, modifies filtration rate as:

$$
F R_{2}(L, T, S)=F R_{1}\left(f_{s 0}+f_{s 1} S+f_{s 2} S^{2}\right)
$$

where $S$ is the ambient salinity.

Increased total suspended solids (TSS, g dry wt $\mathrm{L}^{-1}$ ) reduce the food acquired by hard clams through reduced filtration and increased pseudofeces production (Bricelj \& Malouf 1984, Bricelj et al. 1984, Murphy 1985). The data given in Bricelj and Malouf (1984) and Bricelj et al. (1984) on the percent loss of algae in pseudofeces as a function of sediment concentration were used to develop a relationship that reduces the effectiveness of filtration with increasing TSS concentration. This effect is added to the filtration rate parameterization as:

$$
F R(L, T, S, T S S)=F R_{2}\left(1-a_{T S S} T S S^{b T S S}\right) .
$$

The filtration rate given by Eq. (11) is the value that is input to the hard clam model.

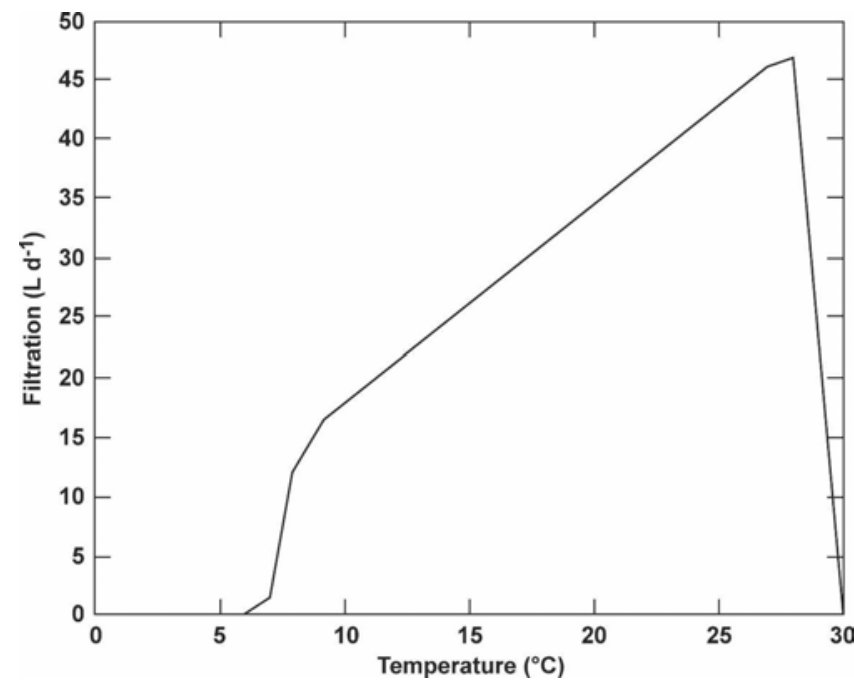

Figure 4. Hard clam filtration rate as a function of temperature calculated using Eq. (9) for a $1 \mathrm{~g}$ dry wt clam.

\section{Assimilation and Assimilation Efficiency}

Assimilation $(A)$ is determined by:

$$
A=F R A E(W) \operatorname{Food}(t)
$$

where filtration rate $(F R)$ is obtained from Eq. (11) and the weightdependent assimilation efficiency, $A E(W)$, determines the fraction of the available food that is assimilated.

The assimilation efficiency consists of a base efficiency $\left(A E_{0}\right)$ for clams less than $30 \mathrm{~mm}$. The base assimilation efficiency is low (Table 1) because the filtration (Eq. 8) and respiration (see Eq. 14, later) relationships produce inordinately high growth rates for small hard clams. The low base assimilation efficiency compensates for this imbalance. The implication is that small hard clams have reduced assimilation, either because of lower filtration rates, less efficient filtration or lower assimilation efficiency because of shorter guts (Hughes 1980, Willows 1992). For larger hard clams, the assimilation efficiency increases in a hyperbolic manner with increasing weight as:

$$
A E(W)=A E_{0}+\frac{A E_{1} W}{A E_{k}+W}
$$

where $A E_{k}$ is the weight (Eq. 3) of a $42.5 \mathrm{~mm}$ hard clam and the asymptotic assimilation efficiency is 0.80 . The food time series $(\operatorname{Food}(t))$ used in Eq. (12) is described in the Environmental Data Sets section.

\section{Respiration}

Respiration is the primary metabolic loss and is parameterized using a general bivalve relationship obtained at $20^{\circ} \mathrm{C}$ (Powell \& Stanton 1985). This relationship was scaled for temperature effects on respiration by using the $Q_{10}$ values for hard clam respiration that are summarized in Grizzle et al. (2000). These values were averaged, except for two that fell outside the range of the others, to obtain a $Q_{10}$ value of 2.75 . The respiration relationship is:

$$
R(W, T)=a_{r} W^{b_{r}} e^{c_{r}\left(T-T_{0}\right)}
$$

which gives increasing respiration rate with increasing temperature (Fig. 5). The respiration rate, in $\mu \mathrm{O}_{2} \mathrm{~h}^{-1} \mathrm{clam}^{-1}$, was converted to energy equivalent units using $4.75 \mathrm{cal}\left(\mathrm{ml} \mathrm{O}_{2}\right)^{-1}, 5000 \mathrm{cal}$ (g dry wt) ${ }^{-1}$ (Hibbert 1977), and $4.184 \mathrm{cal} \mathrm{J}^{-1}$.

\section{Reproduction}

Hard clams are assumed to be sexually mature when they reach $20 \mathrm{~mm}$ (Eversole 2000). For hard clams of this length and larger, positive net production is apportioned into somatic and reproductive tissue using a temperature-dependent reproduction efficiency of the form:

$$
R_{\text {eff }}(T)=R_{1} T-R_{0}
$$

Equation 15 applies over the range of temperatures, reported in Eversole (2000), at which hard clams form reproductive tissue. The temperature-dependent reproductive efficiency, which ranges between zero and 0.9 , determines the fraction of net production that goes into reproductive tissue. The coincidence of positive reproductive efficiency and positive condition index, results in the formation of reproductive tissue. At high temperatures, reproductive tissue formation is limited by scope for growth, which is controlled by the rapid drop in filtration rate above $29^{\circ} \mathrm{C}$ (Eq. 9, Fig. 4) and by the number of days that hard clams experience temperature between $20^{\circ} \mathrm{C}$ and $27^{\circ} \mathrm{C}$, as described in the following section. 


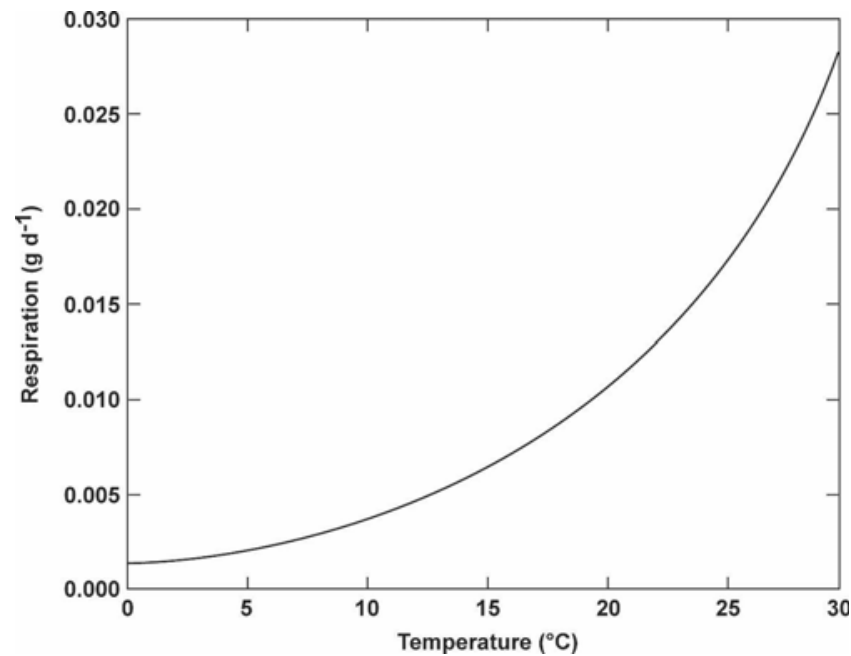

Figure 5. Hard clam respiration rate as a function of temperature calculated using Eq. (14) for a $1 \mathrm{~g}$ dry wt clam.

\section{Egg Production and Spawning}

Spawning occurs when reproductive tissue is a certain fraction of total hard clam body weight and condition index is positive. These criteria, which set a spawning threshold, allow spawning to be dynamically determined by environmental conditions and hard clam condition, rather than being imposed.

The ratio of reproductive tissue to total body weight at which spawning occurs was determined by comparing the simulated number of eggs produced by a spawn to observations (Davis \& Chanley 1956, Bricelj 1979, Bricelj \& Malouf 1980, Malouf 1991, Eversole 2000) that show that an individual hard clam produces 20-40 million eggs in a year. Additional observations (Bricelj \& Malouf 1980) show that the number of eggs produced drops as a function of hard clam weight as length exceeds $60-70 \mathrm{~mm}$, which provides a constraint for simulated spawning.

The number of eggs produced in a simulated spawn was obtained by converting the reproductive tissue to eggs using $51 \mathrm{ng}$ dry wt $\mathrm{egg}^{-1}$ (Eversole 2000). The initial simulations that used a fixed ratio of reproductive tissue to total body weight to trigger spawns overestimated egg production per individual in comparison with observations. Moreover, in some simulations, large hard clams failed to spawn because the scope for growth was inadequate to reach the spawning threshold equivalent to that in the smaller clams. Thus, a spawn ratio $(S R)$ that depends on hard clam weight of the form:

$$
S R=S R_{0}+\left(W-S R_{1}\right) S R_{2}
$$

was developed to provide the trigger for spawning. For hard clams less than $3 \mathrm{~g}$ dry $\mathrm{wt}$, the ratio of reproductive tissue to total body weight at which spawning occurs is 0.2 . As hard clam weight increases beyond $3 \mathrm{~g}$ dry wt, the spawn ratio decreases, reaching a minimum value of 0.08 for clams of $11 \mathrm{~g}$ dry wt. Spawning by larger hard clams is triggered at a lower fraction of reproductive tissue to total body weight, which reduces the number of eggs produced per gram weight for large hard clams (Fig. 6) because the total amount of gamete tissue spawned is smaller, but permits simulated total yearly egg production within the observed range (Eversole 2000).

Hard clams in Great South Bay spawn in June and July, with a small spawn in August (Kassner \& Malouf 1982). Initial simula- tions showed spawning that started at the correct time, but continued into September. The fall spawn resulted in total yearly egg production that was too high relative to observations (Eversole 2000). Observations indicate that spawning of Great South Bay hard clams ceases in the fall, although the processes that terminate spawning have not been identified. Attempts to end fall spawning at the appropriate time that were based on changes in food supply or temperature were unsuccessful. Thus, an ad hoc approach was developed that depends on days when the water temperature is between $20^{\circ} \mathrm{C}$ and $27^{\circ} \mathrm{C}$, a temperature range that brackets the optimal range for hard clam spawning. Days with temperatures in this range add one quality day. Spawning occurs for quality days between 1 and 60; no spawn occurs if the cumulative quality days exceed 60 . This terminates reproduction prior to the fall temperature decrease. The quality day approach resulted in simulated hard clam growth and reproduction that matched observations from Great South Bay. However, this quality day approach may not apply to lower latitude hard clam populations that are observed to spawn later into the fall.

Unspawned gametes are resorbed in the fall when the temperature declines. During times when the temperature is less than $12^{\circ} \mathrm{C}$, the reproductive tissue that is stored as gametes $\left(W_{\text {reprod }}\right)$ is used to support basic metabolic processes at a rate of $0.145 \mathrm{~d}^{-1}$, which results in use of one-half of the gametic tissue in 4.5 days.

\section{Genetic Variations and Development of Cohorts}

Growth of individual hard clams varies in response to physiological characteristics and environmental conditions, which are reflected in the yearly cohorts that ultimately produce the population (Fig. 2). These variations come from the population genetic variability. For example, variations can arise from initial length, which determines an initial physiological state for an individual, and from differences in physiological responses, such as assimilation rate and respiration rate, which influence growth efficiency.

The genetically-determined variability $\left(G V_{i, j}\right)$ of a cohort was obtained using a Gaussian function of the form:

$$
G V_{i, j}=w_{0} e^{\frac{-\left(C 1_{i}-C 1_{0}\right)^{2}}{2 \sigma_{C 1}{ }^{2}}} e^{\frac{-\left(C 2_{j}-C 2_{0}\right)^{2}}{2 \sigma_{C 2}{ }^{2}}}
$$

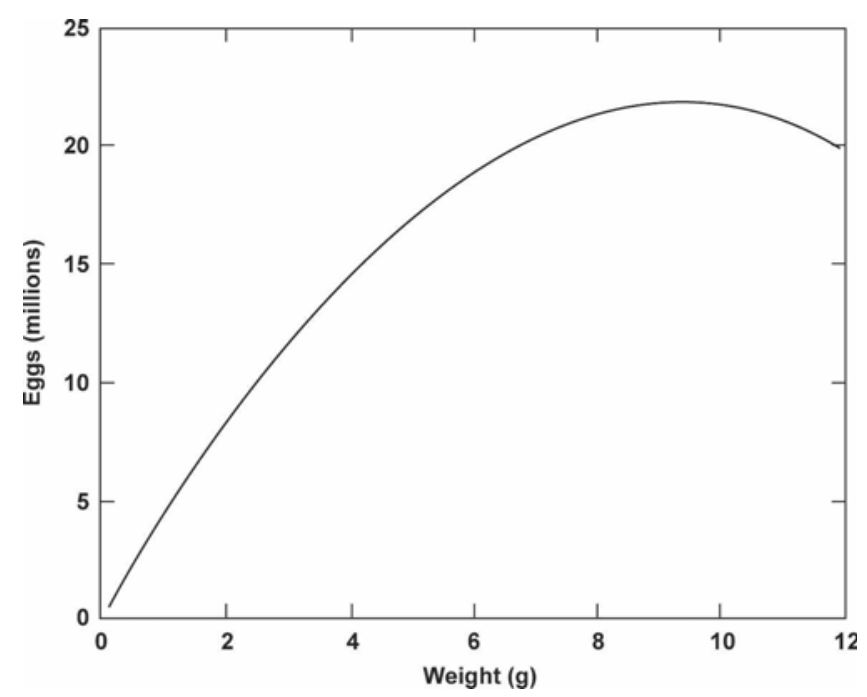

Figure 6. Number of eggs produced as a function of hard clam weight calculated using Eq. (16). 
TABLE 2.

Definitions, units, and values of parameters and coefficients used in calculations of the cohort and population structure.

\begin{tabular}{|c|c|c|c|}
\hline Coefficient & Definition & Units & Value \\
\hline$w_{0}$ & initial clam density & ind $\mathrm{m}^{-2}$ & 1 \\
\hline$C 1_{i}$ & characteristic 1 initial length variation & $\mathrm{mm}$ & specified \\
\hline$C 1_{0}$ & characteristic 1 initial length & $\mathrm{mm}$ & 26 \\
\hline$\sigma_{C 1}$ & characteristic 1 standard deviation & $\mathrm{mm}$ & 6.0 \\
\hline$C 2 j$ & characteristic 2 assimilation rate variation & $d^{-1}$ & specified \\
\hline$C 2_{0}$ & characteristic 2 assimilation efficiency mean value & $d^{-1}$ & 1.0 \\
\hline$\sigma_{C 2}$ & characteristic 2 standard deviation & $\mathrm{d}^{-1}$ & 0.3 \\
\hline imax & maximum range characteristic 1 & none & specified \\
\hline jmax & maximum range characteristic 2 & none & specified \\
\hline$S z_{0}$ & smallest initial length & $\mathrm{mm}$ & 12.0 \\
\hline$S z_{n}$ & largest initial length & $\mathrm{mm}$ & 50.0 \\
\hline$M r_{0}$ & smallest assimilation efficiency value & $d^{-1}$ & 0.25 \\
\hline$M r_{n}$ & largest assimilation efficiency value & $d^{-1}$ & 1.75 \\
\hline$R a$ & broodstock-recruitment constant & ind $\mathrm{g}^{-2}$ & $-3.26 \times 10^{-3}$ \\
\hline$R b$ & broodstock-recruitment constant & ind $\mathrm{g}^{-1}$ & 0.0863 \\
\hline$R c$ & broodstock-recruitment constant & ind $\mathrm{m}^{-2}$ & -0.00228 \\
\hline$B_{t y o}$ & egg survival constant & $(\mathrm{mg} \text { dry } w t)^{2} \mathrm{~g}^{-1}$ & -0.1192 \\
\hline$A_{\text {tyo }}$ & egg survival constant & none & $3.3119 \times 10^{-8}$ \\
\hline$m_{1}$ & mortality rate constant & $\mathrm{d}^{-1}$ & 0.032 \\
\hline$m_{2}$ & mortality rate constant & $\operatorname{age}^{-1}$ & -1.5201 \\
\hline$m_{3}$ & mortality rate constant & $\mathrm{d}^{-1}$ & $1.8916 \times 10^{-4}$ \\
\hline$m_{4}$ & mortality rate constant & $\operatorname{age}^{-1}$ & 0.19016 \\
\hline
\end{tabular}

where $C 1$ and $C 2$ represent the characteristics that are used to specify the genetic variability. The Gaussian distribution was centered about the mean value for each genetic characteristic and the range in variation for each was set by the standard deviation $\left(\sigma_{C 1}\right.$, $\sigma_{C 2}$ ) about the mean value (Table 2). The range in variation associated with a particular characteristic is given by $i$ and $j$. The Gaussian weight is normalized so that

$$
\sum_{i=1}^{i \max } \sum_{j=1}^{j \max } G V_{i j}=1
$$

Equation 17 gives the cohort distribution of two characteristics. It can be expanded to include as many characteristics as are relevant to describing variations in the population.

The estimate of the range of variability in individual hard clams was obtained from data sets that give the range of lengths of hard clams for cohorts at age (Peterson et al. 1983, Grizzle 1988, Kennish unpublished data on 583 hard clams $0.5-10$ y in age). These data were normalized by age and used to derive a relationship that relates the magnitude of the length range to age (Fig. 7). The normalized range suggests a two standard deviation variation in hard clam length at age. This was used as the basis to set the values of $\sigma_{C 1}$ and $\sigma_{C 2}$ in Eq. (17) to give a two standard deviation variation in particular clam characteristics about a mean characteristic value.

Equation 17 was implemented by allowing initial length, assimilation efficiency, and respiration rate to vary. Varying assimilation efficiency is equivalent to varying any process that affects assimilation, including filtration and ingestion rate. Variation in initial length $(S z)$ was introduced by:

$$
S z(i)=S z_{0}+2(i-1) \text { for } i=1, S z_{n}
$$

where $S z_{0}$ and $S z_{n}$ represent the smallest and maximum initial lengths, respectively. Variation in metabolic rates $(\mathrm{Mr})$ was introduced by:

$$
M r(j)=M r_{0}+0.05(j-1) \text { for } j=1, M r_{n}
$$

where $M r_{0}$ and $M r_{n}$ represent the minimum and maximum range for a particular metabolic process. The initial and maximum values used for variation in length and assimilation efficiency are given in Table 2. Some combinations of initial length and metabolic rate will be less common in a given hard clam cohort and other combinations will be less viable overall either because of metabolic imbalances or metabolic inefficiencies. The surviving individuals

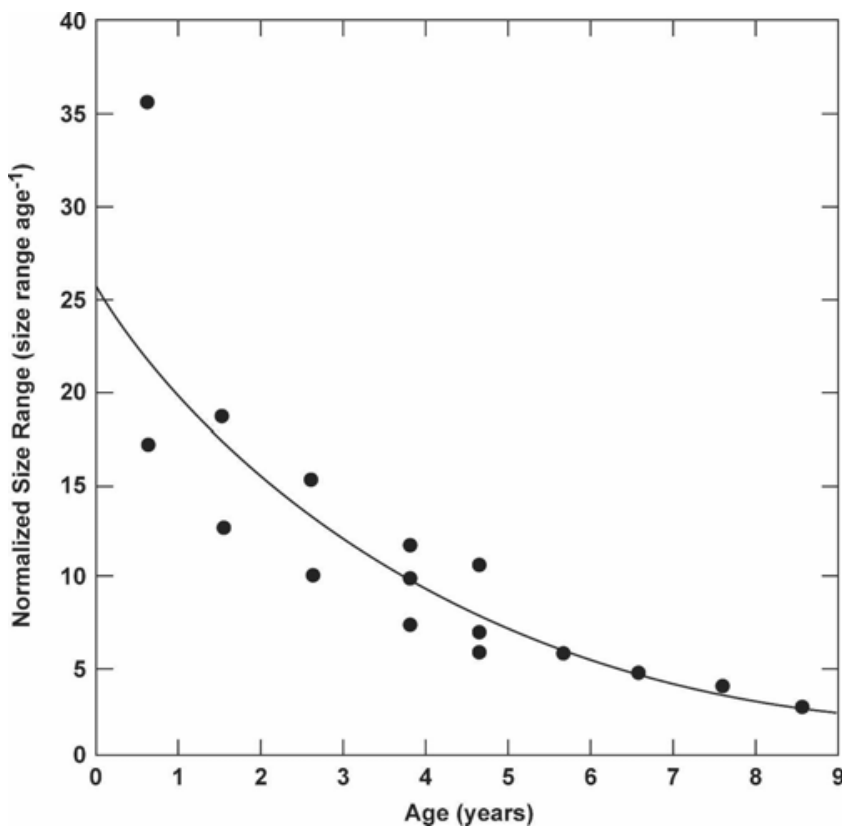

Figure 7. The magnitude of the length range for a hard clam cohort, standardized to cohort age, as a function of cohort age. 
determine the genetic structure of the cohort. A cohort is produced in each year of the simulation and the yearly cohorts concatenated to produce the overall population structure (Fig. 2), as described in later sections.

\section{Mortality}

Simulations were started with 2-y-old hard clams because verification data from Town of Islip, NY stock assessments did not include quantitative counts of younger clams. The postsettlement mortality for the hard clams in the first and second years was absorbed into the recruitment calculation, which is described later. The mortality associated with the two-year and older postsettlement hard clam populations is assumed to be from natural processes, such as predation (Malinowski 1985). Mortality from starvation, temperature, and salinity are considered to be small in comparison and are not included as explicit losses. Combined mortality observations from field estimates and transplanted hard clams (Hibbert 1977, Kennish 1978, Buckner 1984, Walker 1983, Kraeuter unpubl. data) show that the specific mortality rate is higher for young clams, lessens for intermediate age clams, and increases for old clams. These data were used to develop daily specific mortality rates $(M)$ as a function of hard clam age $(C A)$ as:

$$
M(C A)=m_{1} e^{m_{2} C A} \text { for age }<3
$$

and

$$
M(C A)=m_{3} e^{m_{4} C A} \text { for age }>3
$$

where parameter definitions and values are given in Table 2 . The daily specific mortality rates were then used to calculate the fraction of the population that survives $(S F)$ to the next year as:

$$
S F=1-M(C A) T_{y r}
$$

where $T_{y r}$ is the number of days in a year. The survival fraction obtained from Eq. (23) is highest for 2-to-4-y-old hard clams and decreases with age (Fig. 8).

\section{Environmental Data Sets}

\section{Temperature and Salinity}

Several time series of monthly temperature observations are available for Great South Bay. The year-long time series of monthly temperature observations for 1977-1978 (Bricelj 1979) was used for this study because of its completeness and because it appeared to best represent average conditions (Fig. 9A). The seasonal variation in temperature is as expected, with maximum temperatures in summer and minimum values in winter.

The limited available salinity data for Great South Bay (Quaglietta 1987) indicate that salinity variations are small, with maximum values occurring in late summer and fall. The observed salinity variation of Great South Bay is always near optimal levels for hard clams. These data were used to construct an idealized year-long salinity times series (Fig. 9B) in which salinity varies sinusoidally from a minimum of 22.5 to a maximum of 27.5 with the minimum occurring at year-day 100 (April 10).

\section{Chlorophyll $a$ and Food}

Chlorophyll $a$ concentrations for Great South Bay were measured during 1985 at weekly to monthly intervals, except for January, February and March (Quaglietta 1987). The three months for which data were not available were obtained by linear interpola-

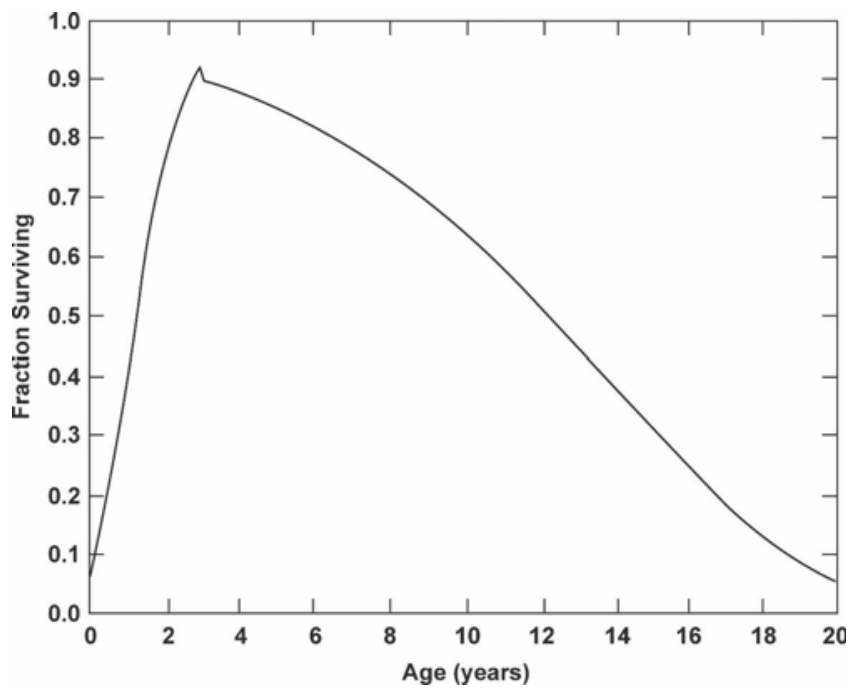

Figure 8. Fraction of hard clams surviving as a function of clam age obtained from Eqs. 21-23. The change in slope of the curve at three years is produced by joining of the two mortality functions.

tion from the nearest measurements. The resultant chlorophyll $a$ time series (Fig. 9C) shows low chlorophyll $a$ from January to late April, after which concentrations about double as the spring bloom develops. Chlorophyll $a$ values during the late summer are reduced from these maximum values and then increase again in late fall (Fig. 9C).
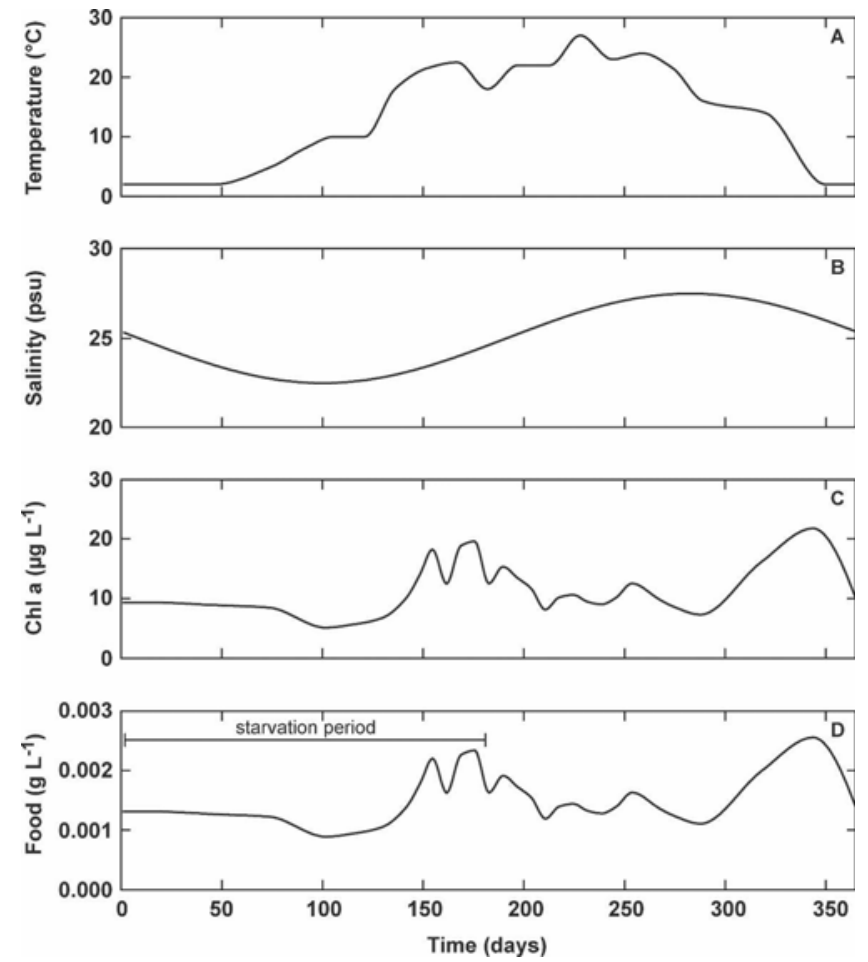

Figure 9. Time series of (A) temperature, (B) salinity, (C) chlorophyll $a$, and (D) food, calculated from chlorophyll $a$ using Eq. (24), that were input to the individual-based hard clam model. The solid line on panel $D$ indicates the time and duration of an imposed starvation period used for other simulations, as described in the text. 
Chlorophyll $a$ concentration (chla) was converted to food (Fig. 9D) using the relationship given in Soniat et al. (1984):

$$
\operatorname{Food}(t)=a f+b f \operatorname{chla}(t)
$$

which includes a nonalgal food supply ( $a f$ ) that increases available food above that estimated from chlorophyll $a$ and sets a lower limit on the food available to hard clams (Table 3). The importance of a nonalgal food source for marine bivalves has been established by independent measurements of protein, lipid, and labile carbohydrate in a number of bays and estuaries (Soniat \& Ray 1985, Soniat et al. 1998, Hyun et al. 2001). The converted food time series (Fig. 9D) was input into the hard clam model via Eq. (12). The food time series resulted in simulated hard clam growth rates that match those reported in Wallace (1991).

\section{Total Suspended Solids}

A wide range in concentration of suspended solids (2-167 mg $\mathrm{L}^{-1}$ ) has been reported for Great South Bay, with increased values associated with periods of high winds or runoff (Dennison et al. 1991). Monitoring activities during the summer of 1980 by Suffolk County, NY showed that suspended solids values usually are below $20 \mathrm{mg} \mathrm{L}^{-1}$ (Dennison et al. 1991). Additional limited measurements of particulate organic matter for Great South Bay (Bricelj et al. 1984) and total seston for Long Island Sound (Evjen 1985) suggest an average concentration of $10 \mathrm{mg} \mathrm{L}^{-1}$. Increases above this value occur in late fall and winter, which is at a time when clam filtration is reduced. The variation in summer values does not exceed this average value (Evjen 1985). Thus, the average total suspended solids concentration was used in the hard clam filtration relationship given by Eq. (11).

\section{Hard Clam Model Implementation}

\section{Solution Method}

The individual-based hard clam model consists of first-order ordinary differential equations that calculate the time-dependent rate of change of weight, length and condition. The dependence among these variables is such that only two are independent and the third can be obtained as a diagnostic calculation. In this implementation of the model, the change in condition and length are obtained from Eqs. (5) and (6), respectively, and are used to calculate weight from Eq. (1).

The set of differential equations is solved with a 5 -stage, $4^{\text {th }}$ -

TABLE 3.

Definitions, units, and values of parameters and coefficients used in implementation of the hard clam and the cohort and population calculations.

\begin{tabular}{cccc}
\hline \hline Coefficient & \multicolumn{1}{c}{ Definition } & \multicolumn{1}{c}{ Units } & Value \\
\hline$a_{f}$ & $\begin{array}{c}\text { non-algal food } \\
\text { concentration } \\
\text { food constant }\end{array}$ & mg dry wt L & 0.520 \\
$b_{f}$ & $\begin{array}{c}\left(\mathrm{mg} \mathrm{dry} \mathrm{wt} \mathrm{L}^{-1}\right) \\
\left(\mu \mathrm{L} \mathrm{L}^{-1}\right)^{-1}\end{array}$ & 0.088 \\
$N_{0}$ & $\begin{array}{c}\text { initial number of } \\
\text { clams } \\
\text { cohort biomass } \\
\text { reduction }\end{array}$ & none & 1 \\
$b f_{0}$ & $\begin{array}{c}\text { cohort biomass } \\
\text { reduction coefficient }\end{array}$ & $(\mathrm{mg} \mathrm{dry} \mathrm{wt)})^{-1}$ & $2.3659 \times 10^{-11}$ \\
\hline
\end{tabular}

order, compact storage Runge-Kutta solution scheme (Carpenter \& Kennedy 1994). This solution procedure has truncation errors proportional to the time step to the fourth power making them accurate in time. The procedure has the further benefit of requiring that only two (instead of the more usual 4) intermediate solutions be saved.

\section{Initial Conditions and Forcing}

The individual-based model was initialized with a two-year-old clam using a range of sizes established by Eq. 19. As a result, simulation year 0 starts with a 2 -y-old clam. Conversion of simulation year to actual clam age is done by adding two years. The hard clam simulations are run for $20 \mathrm{y}$ with a time step of 1 day. The individual-based simulations were combined to form populations with one or more cohorts. A 20-y simulation is sufficient to develop a stable cohort and population structure.

The monthly-averaged environmental data sets input to the model were interpolated to daily values. The annual time series for each environmental variable (Fig. 9) is repeated in each year of the $20-y$ simulation. The simulated weight, length, and condition and additional diagnostic properties, such as egg production, are saved at 10-day intervals. Model calculations are done in terms of $\mathrm{J}$ ( $\mathrm{g}$ dry $w t)^{-1}$.

\section{Cohort and Population Calculations}

A cohort is constructed from the individual-based model results and is composed of individual hard clams that recruit in the same year. The number of individuals $\mathrm{m}^{-2}$ in a cohort at each combination of genetic variability $\left(N_{i, j}\right)$ is calculated as:

$$
N_{i, j}=N_{0} G V_{i, j}
$$

where $N_{0}$ is the initial number of individuals $\mathrm{m}^{-2}$ in the cohort (Table 3) and $G V_{i, j}$ is calculated from Eq. (17). All of the cohort calculations used in this study started with an initial value of 1 ind $\mathrm{m}^{-2}$, which is consistent with observed hard clam abundances in Great South Bay. The initial value is then apportioned among the various genetic combinations obtained by application of Eq. (17).

Age-dependent mortality, obtained from Eqs. $(21,22)$, is applied to the cohort and the annual survival fraction (Eq. 23) is used to calculate the reduction in total number of clams in a cohort in a given year as:

$$
N_{i, j}(\text { year })=S F \times N_{i, j}(\text { year })
$$

The total cohort biomass $\mathrm{m}^{-2}(C B)$ is then obtained by summing the product of the number of hard clams associated with each genetic characteristic and the corresponding weight that each has in the month of June $\left(J W_{i, j}\right)$ :

$$
C B=\sum_{i=1}^{i \max } \sum_{j=1}^{j \max } N_{i, j} \times J W_{i, j}
$$

The simulated June weight is used in the above calculation because this corresponds to the maximum (prespawn) weight for an individual hard clam.

The population biomass in a given year $(P B($ year $))$ is determined by summing across all cohorts

$$
P B(\text { year })=\sum_{k=1}^{C m a x} C B_{k}
$$

where $k$ represents the number of cohorts and Cmax is the maximum number of cohorts. The total population biomass obtained 
from Eq. (28) provides the spawning stock biomass that is used to calculate the number of surviving eggs (Eq. 30), as described below.

\section{Population Recruitment}

The number of eggs spawned provides the potential recruits that produce a cohort in a given year. Simulated egg production for the spawning stock cannot be converted simply into recruitment, however. A broodstock-recruitment relationship derived for Great South Bay hard clam populations suggests that survivorship varies nonlinearly as a function of broodstock biomass. This relationship was developed using data collected by the Town of Islip, NY, from 1978-2000 expressed as the number of 2-y-old clams in a given year as a function of broodstock biomass two years previously. This relationship is of the form:

$$
R(\text { year })=R a \times P B(\text { year }-2)^{2}+R b \times P B(\text { year }-2)+R c
$$

where $R$ (year) is the number of 2 -y-old clams $\mathrm{m}^{-2}$ in a given year and $P B($ year -2$)$ is the spawning stock biomass in $\mathrm{g} \mathrm{m}^{-2}$ that existed two years previously. Kraeuter et al. (2005) provide additional information on the relationship between recruitment and broodstock in Great South Bay hard clam populations.

The relationship given by Eq. (29) results in a linear increase in recruits with increasing broodstock biomass up to a certain biomass, after which recruits level off as biomass increases, a process known as compensation. Compensatory processes involve cannibalism of young (e.g., Hunt et al. 1987) or competition for food among adults (Frechette \& Lefaivre 1990, Honkoop \& Bayne 2002), which may reduce fecundity. A nonlinear dependency of spat density on spat survival, which may arise from variable predation rates over a range of clam densities (Peterson et al. 1995, Boulding \& Hay 1984), would also produce a compensatory broodstock-recruitment pattern.

The broodstock-recruitment relationship given by Eq. (29) does not allow variations in recruitment in years when environmental conditions increase or restrict fecundity or survivorship for a given broodstock biomass. Therefore, the broodstock-recruitment relationship was used with an empirically-derived relationship between clam biomass and fecundity to determine egg survivorship. The biomass-fecundity relationship was obtained by first creating an average population length-frequency distribution from the Town of Islip hard clam data. Simulations using average environmental conditions for Great South Bay (described in the Environmental Data Sets section) were used to obtain hard clam egg production values for a wide range of hard clam lengths and weights. These egg-production values were prorated across the average length-frequency distribution to create a population average fecundity and the fecundity value was normalized to a broodstock value of $1 \mathrm{~g}$ dry wt $\mathrm{m}^{-2}$. The $1-\mathrm{g}$ dry $\mathrm{wt}-\mathrm{m}^{-2}$ value was then expanded across the range of anticipated population biomasses obtained from the broodstock-recruitment curve, with the assumption that the source of compensation in the biomass-recruitment curve is not adult competition for resources. In Great South Bay, average hard clam biomass does not normally exceed about 3 large clams $\mathrm{m}^{-2}$ and this density is unlikely to create conditions limiting clam ingestion, thereby producing competition for resources.

The clam biomass-fecundity relationship was used with the estimate of the number of two-year-old recruits obtained from the broodstock-recruitment curve for a given population biomass to obtain the average egg survivorship to a 2 -y-old clam for a range of population biomass levels. The resulting relationship describing the fraction of eggs surviving to become two-year-old clams $\left(S_{t y o}\right)$ as a function of population biomass is of the form:

$$
S_{t y o}=A_{t y o} e^{T_{t y o} P B(\text { year }-2)} \text { Eggs }
$$

where parameter definitions and values are given in Table 2. Eq. (30) gives decreasing survivorship with increasing hard clam biomass, thus maintaining the general compensatory relationship defined by the broodstock recruitment curve, while also allowing conditions of inherently higher fecundity to result in inherently higher recruitment.

A hard clam population is constructed from the yearly cohorts. In each year, a new cohort enters the population with a number of individuals and size structure as described by Eq. (19) and (30). As a consequence, population age frequency and length frequency are independent characteristics, length being derived from the growth of each individual genotype in each cohort and age by the time of cohort birth.

\section{RESULTS}

\section{Individual Hard Clam Simulations}

\section{Individual Hard Clam Reference Simulation-Basic Characteristics}

The simulated length and weight change of an average individual hard clam (Fig. 10) followed the normal pattern, with increases in weight being larger for smaller-sized clams and length increases being greater for larger clams. Decreases in weight, such as the one that occurs at about $40 \mathrm{~mm}$, result from spawning. For Great South Bay environmental conditions, the simulated length and weight remain above the standard curve, except when spawning occurs, and never exceed the maximum length and weight allowed for hard clams.

The simulated hard clam dry weight (Fig. 11A) increases during the first five simulation years, after which the rate of increase in dry weight declines and levels out at $4-5 \mathrm{~g}$. The short-term decreases in weight are associated with spawning, which is most frequent in simulation years 2 and 3 (hard clam years 4 and 5). Short-term fluctuations in weight decrease in the later years of the

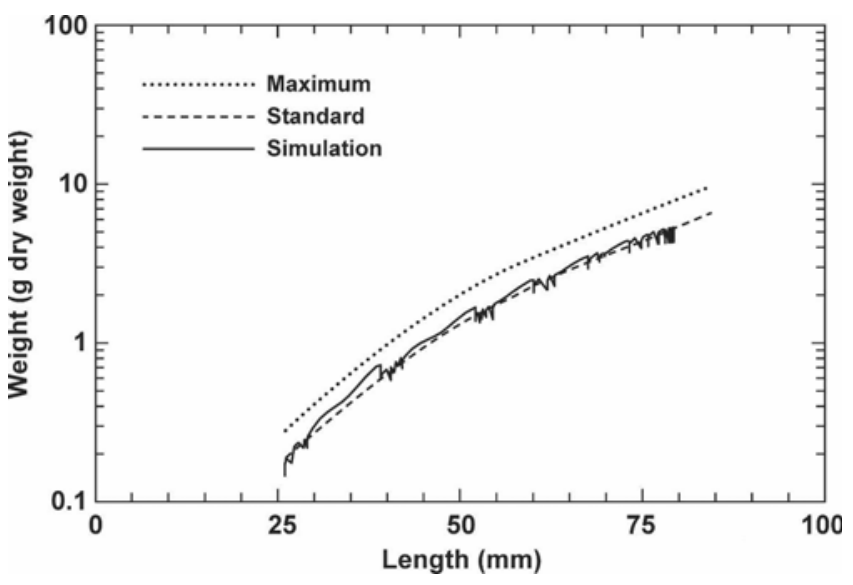

Figure 10. Simulated hard clam length and weight obtained from the reference simulation with the individual-based model. The standard and maximum hard clam length-weight curves obtained from Eqs. 3 and 4, respectively, are shown for comparison. Decreases in simulated hard clam weight at a given length are associated with spawning events or times of negative scope for growth. 
simulation as the hard clam gets larger and older and spawns less frequently. The weight decrease that begins in winter and extends into the spring of each simulation year results from reduced food (Fig. 9D) during this time. The simulated change in hard clam length (Fig. 11A) is rapid in the first five simulation years, after which length increases slowly to a maximum value of about 79 $\mathrm{mm}$. The periods of constant length in each simulation year coincide with periods of weight loss, such as occurs during the winter and spring.

The reference simulation is for a hard clam with an average genotype for the cohort as defined by Eqs. (19) and (20). As a consequence, some members of the cohort will grow slower and others faster than this average animal. Likewise, some spawn more and others less frequently. This is then a representative hard clam genotype for the cohort, but not the only genotype. The simulated condition index (Fig. 11B) of this average hard clam ranges between 0.4 and -0.4 . Positive condition corresponds to times of increase in weight and shell length and occur mostly during the
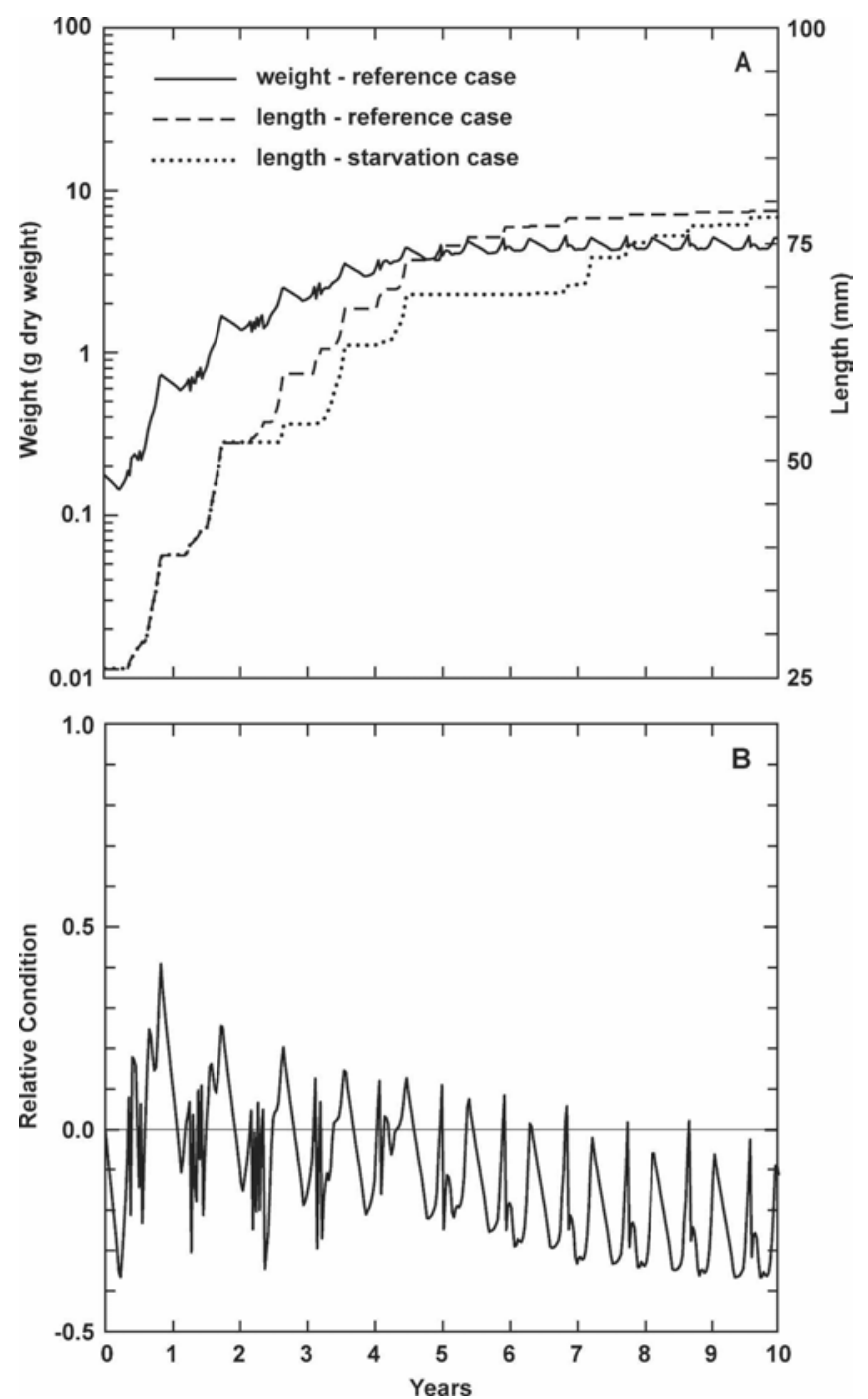

Figure 11. Simulated time development in (A) hard clam weight and length obtained from the reference simulation and a simulation that included a starvation period (cf. Figure 9D) and (B) condition index obtained from the reference simulation. Note that weight and length are given on log and linear scales, respectively. first five simulation years. Positive condition is also associated with spawning (Fig. 11A) after which condition declines, normally becoming negative. Periods of negative condition also occur during times of reduced food availability, such as in winter (Fig. 9D). At these times, weight decreases as the hard clam resorbs tissue to cover metabolic needs and length remains constant (Fig. 11A). After simulation year 5, the variability in condition index is reduced (Fig. 11B) because of less frequent spawning. After the first five simulation years (clam age of $7 \mathrm{y}$ ) the trend in condition index is negative, with only occasional short-duration periods of positive condition. Condition index remains negative after simulation year 9 (clam age of $11 \mathrm{y}$ ).

The negative condition characteristic of the latter stages of hard clam development is expected. Growth slows with increasing age because the time-integrated amount of energy assimilated begins to be balanced by the losses to respiration and reproduction. For the simulated shell growth to slow, as observed at old age, condition index must rarely rise above zero, as positive condition leads to shell growth. The expected rise and fall of condition index with the yearly gametogenic cycle (Fig. 11B) differs from the overall trend in relative condition over the animal's lifetime that describes the decline in growth efficiency as animal size increases (Thompson \& Bayne 1974, Hawkins \& Bayne 1992, Brown et al. 1993, Lika \& Nisbet 2000). This constraint in energy apportionment is also seen in spawning. Spawning is a frequent and regular event during the first four simulation years (clam age of 2-6 y) of the representative animal and spawning season spans much of the summer (Fig. 12A). The number of eggs spawned increases during the first four simulation years (Fig. 12A). In subsequent years, spawning normally occurs once yearly and the number of eggs produced is relatively constant.

\section{Individual Hard Clam Reference Simulation—Sensitivity Studies}

Exposure to a six-month period without food (Fig. 9D), beginning at the start of simulation year 3 , produces starvation and results in a cessation of hard clam growth (Fig. 11A), reduced spawning frequency and egg production (Fig. 12B), and an extended period of negative condition index (Fig. 13). Once food is again available, length increases (Fig. 11A). Spawning frequency and egg production in the following two simulation years (years 4 and 5) is more frequent than observed in the nonstarved simulation (Fig. 12A,B). An additional starvation period in simulation year 6 again results in cessation of growth but the final hard clam length after $10 \mathrm{y}$ of simulation is similar to that obtained from the simulation in which food was available at all times. This rebound effect is well known (e.g., Engle \& Chapman 1953, Kobayashi et al. 1997) and originates from the inherently higher growth efficiencies of smaller animals that allows them to appear to "catch up" in growth when energy limitation ceases. Again, spawning frequency and egg production are reduced by starvation (Fig. 12B). Although starvation events do not seem to have a long-term effect on hard clam growth, as indicated by length, there is an effect on reproductive capacity (Fig. 12B).

An assumption made in the development of the individualbased model is that small hard clams have lower assimilation efficiency (Eq. 13). The importance of this assumption is demonstrated by a simulation in which the assimilation efficiency of small hard clams was not reduced. In the first $0.5 \mathrm{y}$ of the simulation, when individuals are less than $30 \mathrm{~mm}$, condition index exceeds 0.5 (Fig. 13), a value well above the condition index 

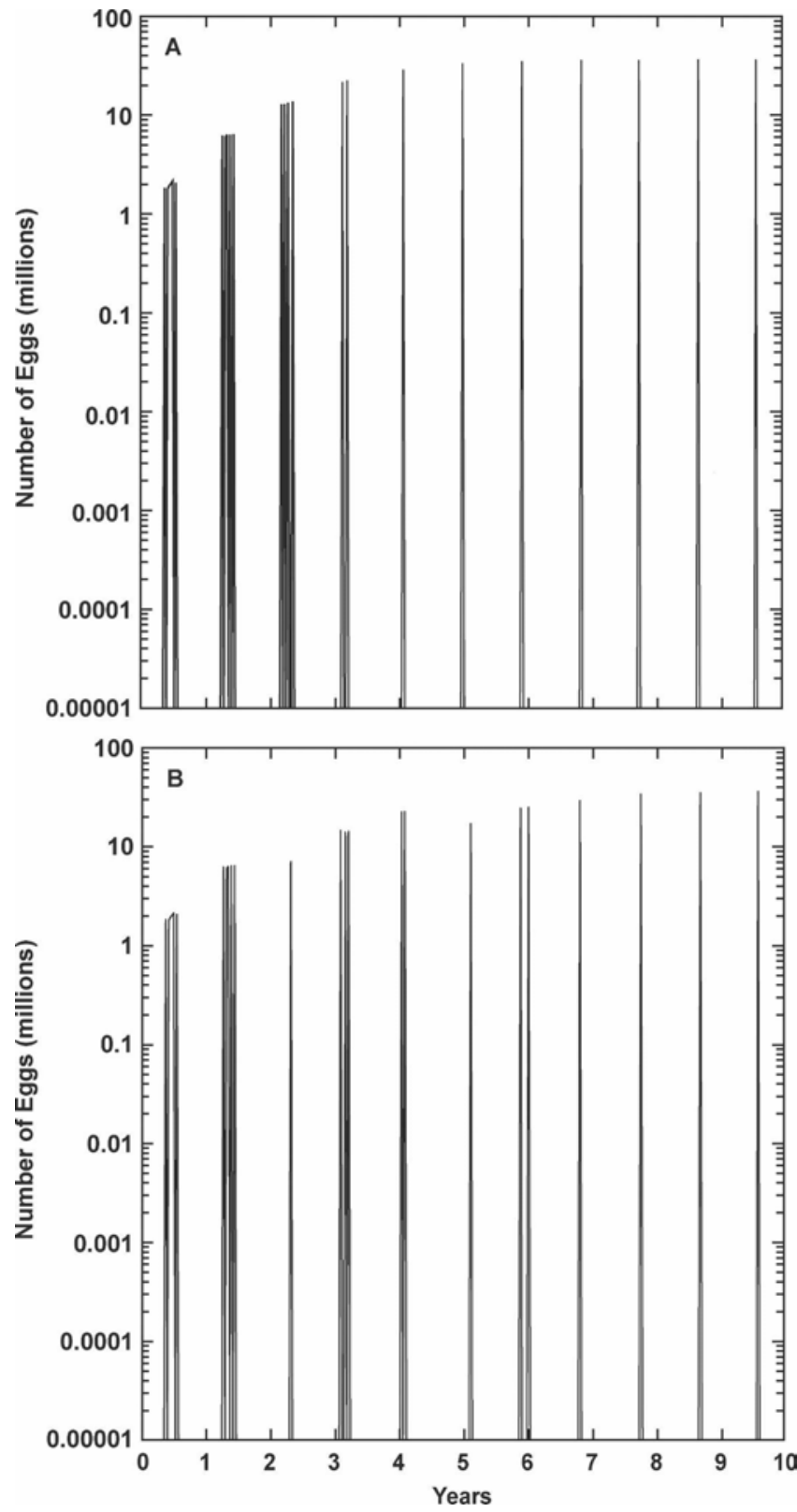

Figure 12. Simulated change in the timing and magnitude of the number of eggs spawned by hard clams exposed to (A) standard food conditions and (B) standard food conditions with an imposed starvation period (Figure 9D).

obtained from the simulation that assumed reduced assimilation efficiency (Fig. 11B). The resultant growth rate for small hard clams is unrealistic.

\section{Hard Clam Cohort Simulations}

\section{Hard Clam Cohort Reference Simulation-Basic Characteristics}

The individual hard clam simulations were combined via Eq. (17) to produce a cohort with genetic variation imposed through variability in assimilation efficiency and initial length. The lengthfrequency distribution of the cohort produced from the individual-

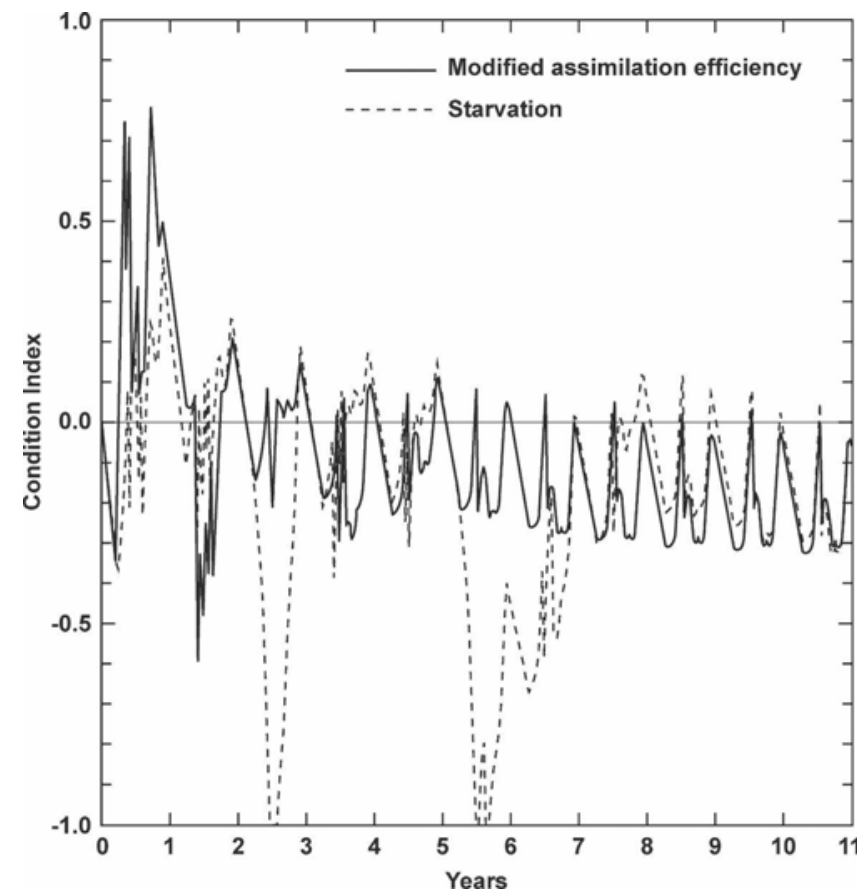

Figure 13. Simulated change in hard clam condition index that occurs in response to relaxing the constraint of reduced assimilation efficiency for small clams (Eq. 13) and to imposing a starvation period (Figure 9C).

based reference simulation (Fig. 14A) shows an initial large peak at $25 \mathrm{~mm}$ that decreases in amplitude as the cohort ages and mortality has an effect. The range of lengths included in the cohort increases with age. For example, the cohort in simulation year 4 (clam age year 6) ranges from about $30 \mathrm{~mm}$ to almost $75 \mathrm{~mm}$. This expansion of cohort length range with age is well described (Craig \& Oertel 1966, Powell et al. 2005).

Cohort biomass (Fig. 14B) begins to increase in simulation year 2 , peaks in simulation years 4 and 5 (clam age years 6 and 7) as growth exceeds mortality, after which it decreases to low levels in simulation year 15 and beyond. Cohort egg production is highest in simulation years 2-5 (clam age years 4-7), and declines in later years (Fig. 14B). Much of this trend originates from the increase in fecundity of young clams as they grow and the decline in cohort fecundity with age, as the clams die. The number of survivors in the cohort declines over the simulation, reaching essentially zero after simulation year 12 (Fig. 14B).

\section{Hard Clam Cohort Reference Simulation-Sensitivity Studies}

The effect of reduced and increased range in genetic variability on cohort structure was tested. Genetic variability was modified by changing the values of $\sigma_{C 1}$ and $\sigma_{C 2}$ in Eq. (17): smaller values yield a restricted range and larger values give an expanded range. The cohort structure produced by a restricted range of genetic variability (Fig. 15A) is similar to that obtained from the basic simulation (Fig. 14A), but with an unrealistic reduction in the spread in length within the individual cohorts. The number of individuals in the modal size class of the cohort is larger than that obtained in the reference simulation because the narrow range of genetic variability retains more individuals in a narrower range of length classes. The expanded range of genetic variability results in 

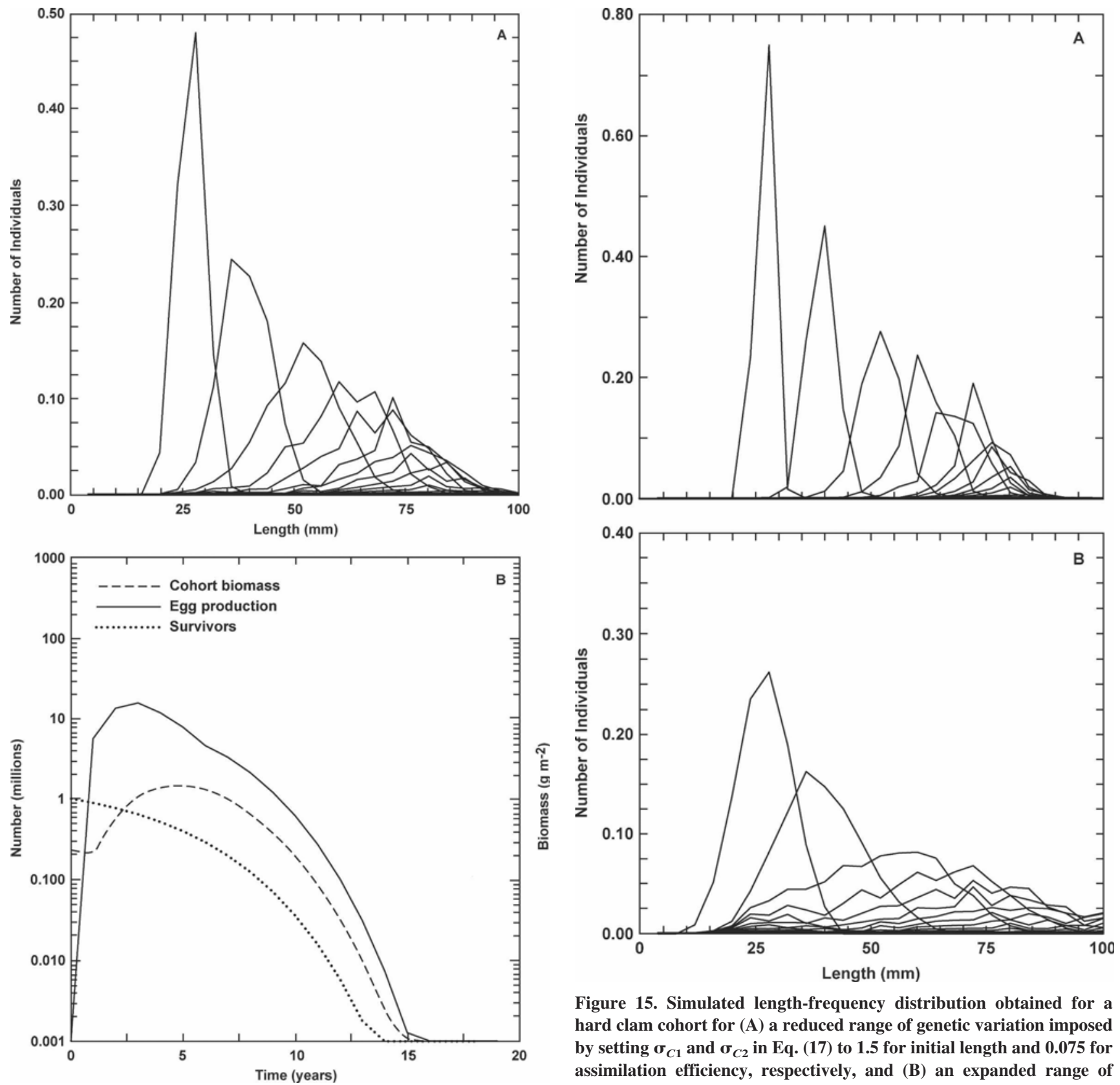

Figure 15. Simulated length-frequency distribution obtained for a hard clam cohort for $(\mathrm{A})$ a reduced range of genetic variation imposed by setting $\sigma_{C 1}$ and $\sigma_{C 2}$ in Eq. (17) to 1.5 for initial length and 0.075 for assimilation efficiency, respectively, and (B) an expanded range of genetic variation imposed by setting $\sigma_{C 1}$ and $\sigma_{C 2}$ in Eq. (17) to 6.0 for

Figure 14. Simulated (A) length-frequency distribution and (B) time development of cohort biomass, egg production, and recruitment constructed from results of individual hard clam simulations subject to the standard environmental conditions (Figure 9) and standard genetic range for initial length and assimilation efficiency (Table 2).

considerable, and again unrealistic, spreading of the cohort (Fig. 15B). Cohorts for simulation years 4 and higher (clam age years 6 and higher) essentially include animals of all lengths.

Respiration rate is another physiological characteristic that produces genetic variability in hard clams. Variation in respiration rate and initial length produces a cohort structure (Fig. 16A) that is similar to that obtained using assimilation efficiency and initial length, but the number of individuals in the older cohorts is too large.

The cohort structure that results when respiration rate and assimilation efficiency are varied together is also unrealistic (Fig.

16B) because the length range of 2-y-old clams at the beginning of the simulation is not adequately represented by a single initial length. The length effect disappears in later simulation years to produce cohort length distributions that are similar to those obtained by variations in assimilation efficiency and initial length (Fig. 14). Assimilation efficiency and respiration are in many ways equivalent physiological processes because each varies scope for growth. However, assimilation efficiency introduces a wider range of variability in cohort length structure and more accurately reproduces known cohort length structures, when only a single physiological characteristic is considered.

The interaction between clam initial length and variation in physiological rate is reflected in the distribution of clam lengths in the cohort at age 7 (simulation year 5). Low assimilation efficiency 

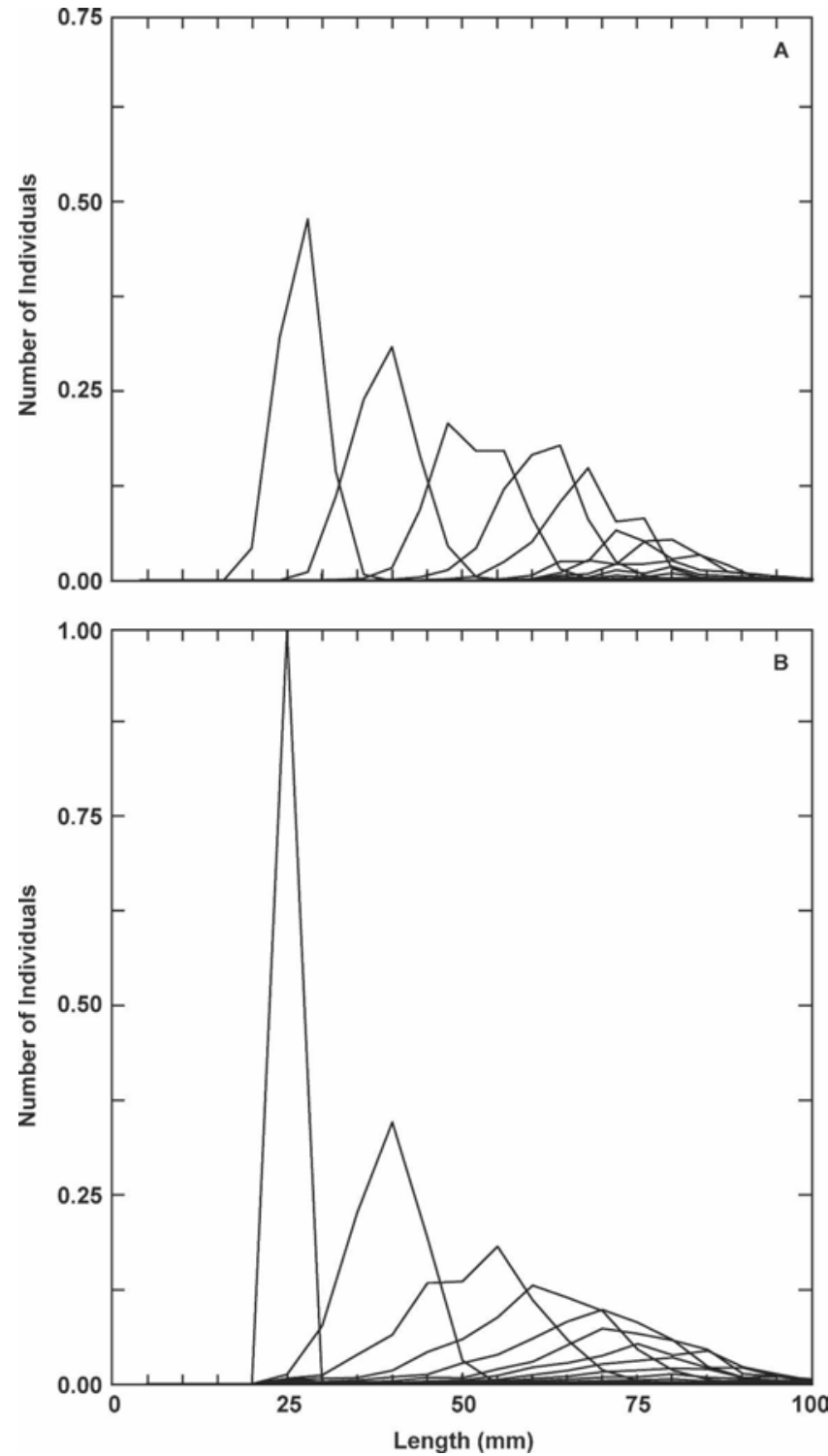

Figure 16. Simulated length-frequency distribution obtained for a hard clam cohort in which the population characteristics used to represent genetic variability were (A) initial clam length and respiration rate and (B) respiration rate and assimilation efficiency. The values of the genetic ranges are given in Table 2. The range of variation in respiration rate was assumed to be the same as for assimilation efficiency.

(less than 0.75 of the mean) results in hard clams that are $<48 \mathrm{~mm}$ after $5 \mathrm{y}$, for all initial lengths (Fig. 17A). Production of clams larger than $85 \mathrm{~mm}$ requires assimilation efficiencies that are $>1.25$ times the mean rate, which gives a greater scope for growth. Variation of respiration rate over the same range gives larger clams for the same amount of change than does variation in assimilation efficiency (Fig. 17B). The implication is that larger clams are the more metabolically efficient, with lower weight-specific respiration rates. Changes in initial clam length for a given variation in respiration rate produce minor, but important modifications, to these trends.

The effect of variations in assimilation efficiency and initial length on total egg production is to constrain genotypes characterized by low assimilation efficiency and small initial size (Fig. 18A). Because more clams have average genotypes, the Gaussian-
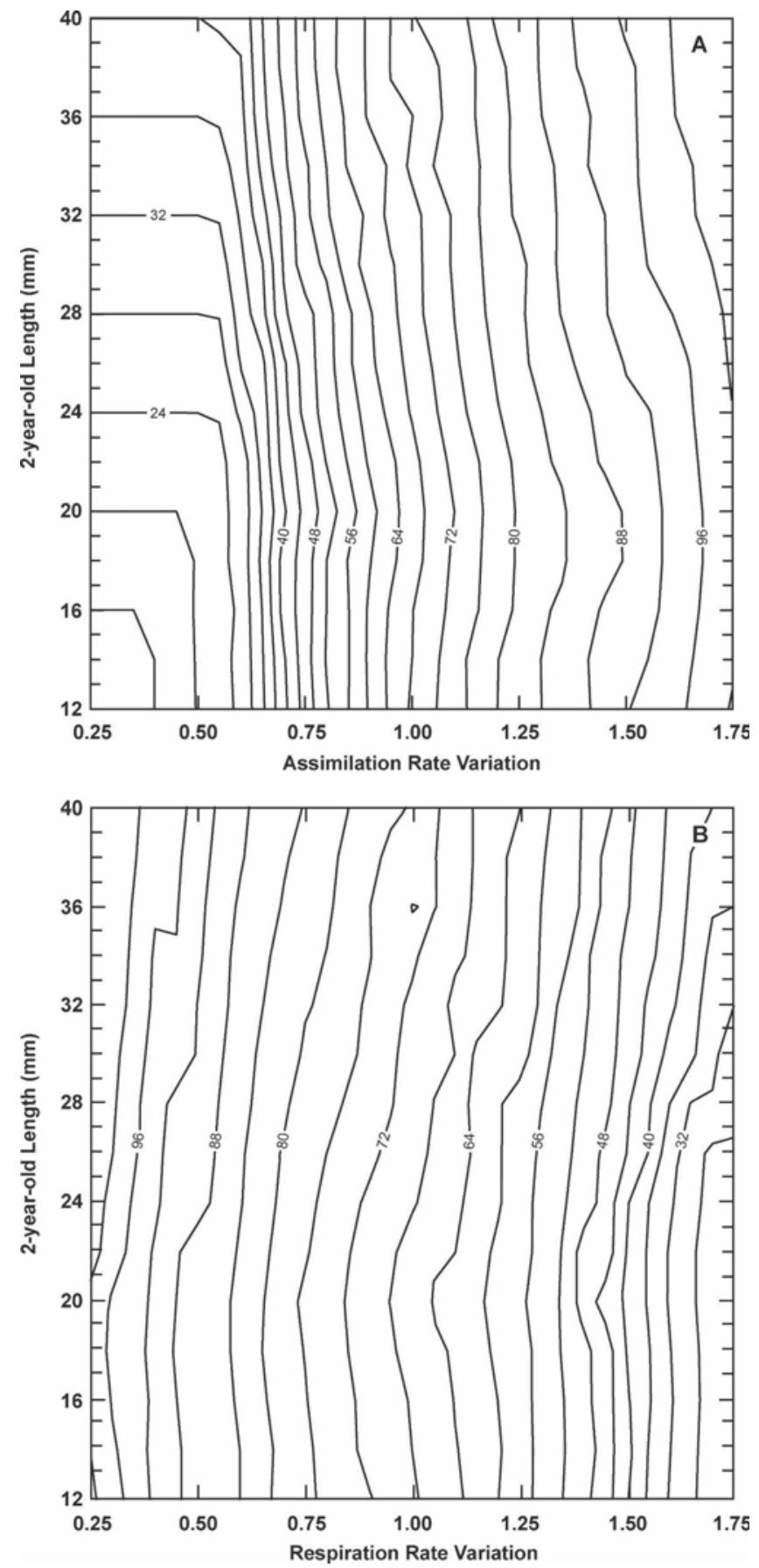

Figure 17. Simulated final length $(\mathrm{mm})$ obtained for a hard clam cohort after five simulation years in which the population characteristics used to represent genetic variability were $(A)$ initial clam length and assimilation efficiency and $(B)$ initial clam length and respiration rate. The $x$-axis values represent the fraction of the mean value of all cohort genotypes as expressed by Eq. (17). The range in variation for respiration rate was assumed to be the same as for assimilation efficiency.

weighted egg production of the cohort will be highest near the center of the distribution, all else being equal. Assimilation rates (Fig. 18A) that are lower than the mean rate $(<1)$ compress the Gaussian distribution, as these animals' scope for growth is insufficient to permit normal fecundity. Similarly, respiration rates that are higher than the mean rate $(>1)$ (Fig. 18B) compress the Gaussian distribution, as high respiration debits energy that might oth- 
erwise go into reproduction. The Gaussian-weighted egg production produced from the combination of respiration and assimilation efficiency rates (Fig. 18C) is slightly off center, indicating that the dominate members of the cohort responsible for reproduction are not the numerically most common genotypes. The most common genotype is at the center of the diagram $(1.0,1.0)$, whereas the center of egg production is below and to the right of this point (1.1, $0.95)$.

\section{Hard Clam Population Simulations}

Hard Clam Population Reference Simulation-Basic Characteristics

Concatenation of the yearly cohorts produced over a twentyyear simulation (Fig. 19A) results in a simulated hard clam population structure with two distinct abundance peaks centered around $25 \mathrm{~mm}$ and $40 \mathrm{~mm}$ and two smaller peaks at $60 \mathrm{~mm}$ and $70 \mathrm{~mm}$. Highest abundance is associated with the newest cohort of 2-y-old clams at $25 \mathrm{~mm}$ modal size. The number of individuals at a given length (Fig. 19B) shows that most of the population is between 25 $\mathrm{mm}$ and $70 \mathrm{~mm}$. For lengths greater than $70 \mathrm{~mm}$, the number of individuals decreases as old-age mortality takes a toll.

The relationship between hard clam biomass and abundance (Fig. 19C) describes a trajectory that is followed as yearly cohorts are added to the population. The hard clam population initially peaks at about $2 \mathrm{~g}$ biomass and 0.8 individuals $\mathrm{m}^{-2}$ in year 4 , after which it approaches a stable biomass of 6-7 $\mathrm{g}$ at an abundance of about 0.75 individuals $\mathrm{m}^{-2}$. The population fluctuation that occurs as the first few cohorts are added is an artifact of model initialization and adjustment. The stability in the population after this adjustment represents a balance between the supportable biomass, the weight-dependent decline in fecundity in older clams, and the broodstock-recruitment relationship. Thus, the environmental conditions used in the reference simulation can support 6-7 $\mathrm{g}$ of hard clams, either as a few large or many small clams. The final simulated population abundance is typical of present day Great South Bay hard clam populations (Kraeuter et al. 2005).

The characteristics of the simulated population length frequency stem from an initial mode, centered around $25 \mathrm{~mm}$ (lower left, Fig 20A), which moves towards larger lengths over time. This mode is associated with the initial cohorts, which increase in length during the first few years of the simulation. After the initial adjustment years, the fraction of the population at a given length is relatively constant. A second mode appears after simulation y 4, again centered at $25 \mathrm{~mm}$, which represents new recruits, which increase in length over time and are gradually absorbed into the larger length classes established by the initial cohorts. The hard clam population age-length structure after $20 \mathrm{y}$ of simulation (Fig. 20B) shows that the fraction of the population at a given length spreads in age with increasing length and that the fraction of the population at a given age spreads in length as the population ages.

\section{Hard Clam Population Reference Simulation-Sensitivity Studies}

The simulated population structure is dependent on the form used for the broodstock-recruitment relationship (Eq. 30). Thus, the sensitivity of the population structure to different forms of this relationship was tested. The population structure that is produced by a broodstock-recruitment curve with no density-dependent control on population growth (Fig. 21A) shows more individuals $\mathrm{m}^{-2}$ and proportionately more smaller clams than obtained from the reference simulation (Fig. 19A). An equilibrium is not reached as each year sees an increase in the abundance of nearly all size classes (Fig. 21A). As a consequence, the population abundance at the end of the simulation is higher than observed for Great South Bay hard clam populations (Fig. 21B). The population age-length relationship is elongated towards larger animals (Fig. 22A) and curves upwards in age. The curvature indicates that large animals achieve higher abundance, which is consistent with no densitydependent controls. This is further indicated by the population trajectory (Fig. 22B), which shows an unconstrained increase in population biomass and number of individuals $\mathrm{m}^{-2}$ over the $20-\mathrm{y}$ simulation.

Increasing the strength of the density-dependent control in the broodstock-recruitment relationship results in a simulated population structure in which the number of individuals $\mathrm{m}^{-2}$ (Fig. 23A) and the biomass (Fig. 23B) are reduced relative to the reference simulation (Fig. 19A, B). The relationship between population biomass and abundance (Fig. 23C) shows an initial adjustment, after which the population reaches a stable value of about $4 \mathrm{~g}$ at 0.4
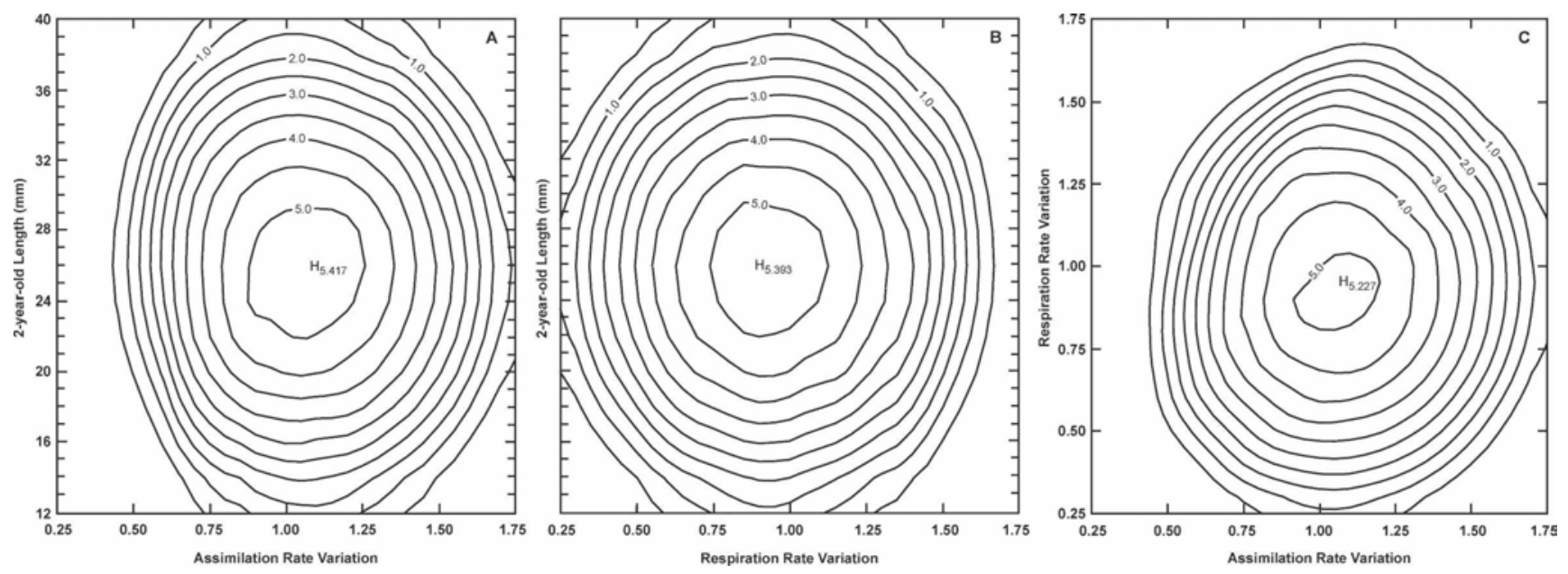

Figure 18. Egg production (contours are $\log _{10}$ eggs produced) after five simulation years for a hard clam cohort with genetic variability introduced through variations in: (A) initial clam length and assimilation efficiency, (B) initial clam length and respiration rate and (C) respiration rate and assimilation efficiency. The $x$-axis values represent the fraction of the mean value of all cohort genotypes as expressed by Eq. (17). The range in variation for respiration rate was assumed to be the same as for assimilation efficiency. The number of eggs produced by a cohort is determined by the fecundity of the individual hard clam and the abundance of the genotype in the cohort. 

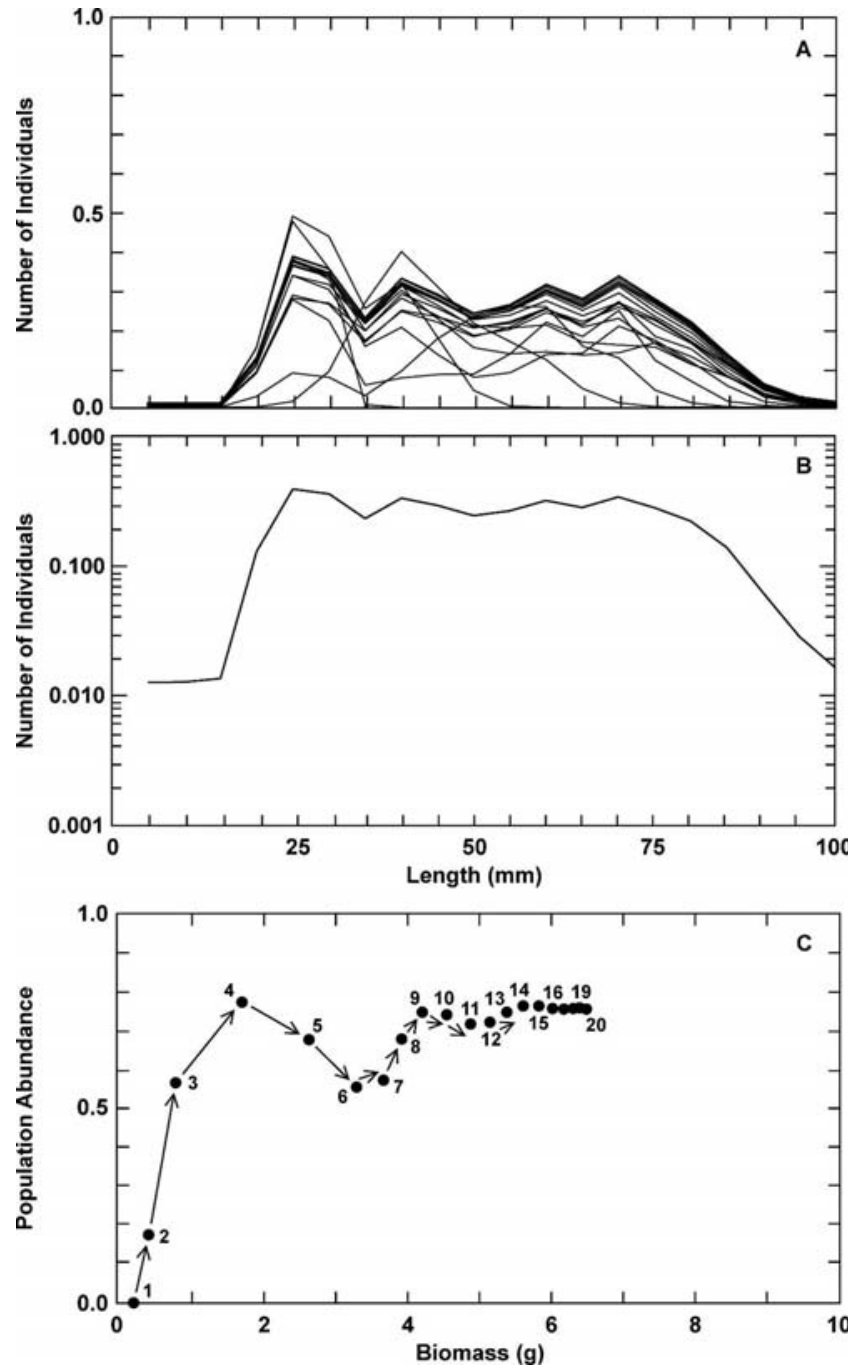

Figure 19. Simulated (A) population structure produced by summing a series of cohorts in which each line represents the length frequency of the population in a given year, $(B)$ number of individuals at a given length in the population on a log scale and (C) the time history of population abundance as a function of biomass for hard clam populations exposed to the standard environmental conditions (Fig. 9) and for which genetic variability was represented by initial clam length and assimilation rate (Table 2). The superposed lines in the lengthfrequency distribution (A) identify the most stable age structure for the population.

ind $\mathrm{m}^{-2}$ and a stable length frequency (Fig. 23A). Abundance is too low, however, relative to observed hard clam population abundances in Great South Bay.

Natural mortality rate also affects the simulated population structure. Increasing the mortality rate for 40-to-60-mm hard clams produces a stable population structure (Fig. 24A), but the number of individuals $\mathrm{m}^{-2}$ at a given length is about an order of magnitude less than that obtained for the reference simulation (Fig. 24B versus Fig. 19B). The population abundance as a function of population biomass stabilizes at a value of about $0.05 \mathrm{~g}$ and 0.15 ind $\mathrm{m}^{-2}$ (Fig. 24C), values much below those observed for Great South Bay hard clam populations. Removal of the intermediate-size clams at an increased rate skews the population age-length relationship (Fig. 25) towards smaller lengths and younger ages by limiting the number of animals that grow to large size.
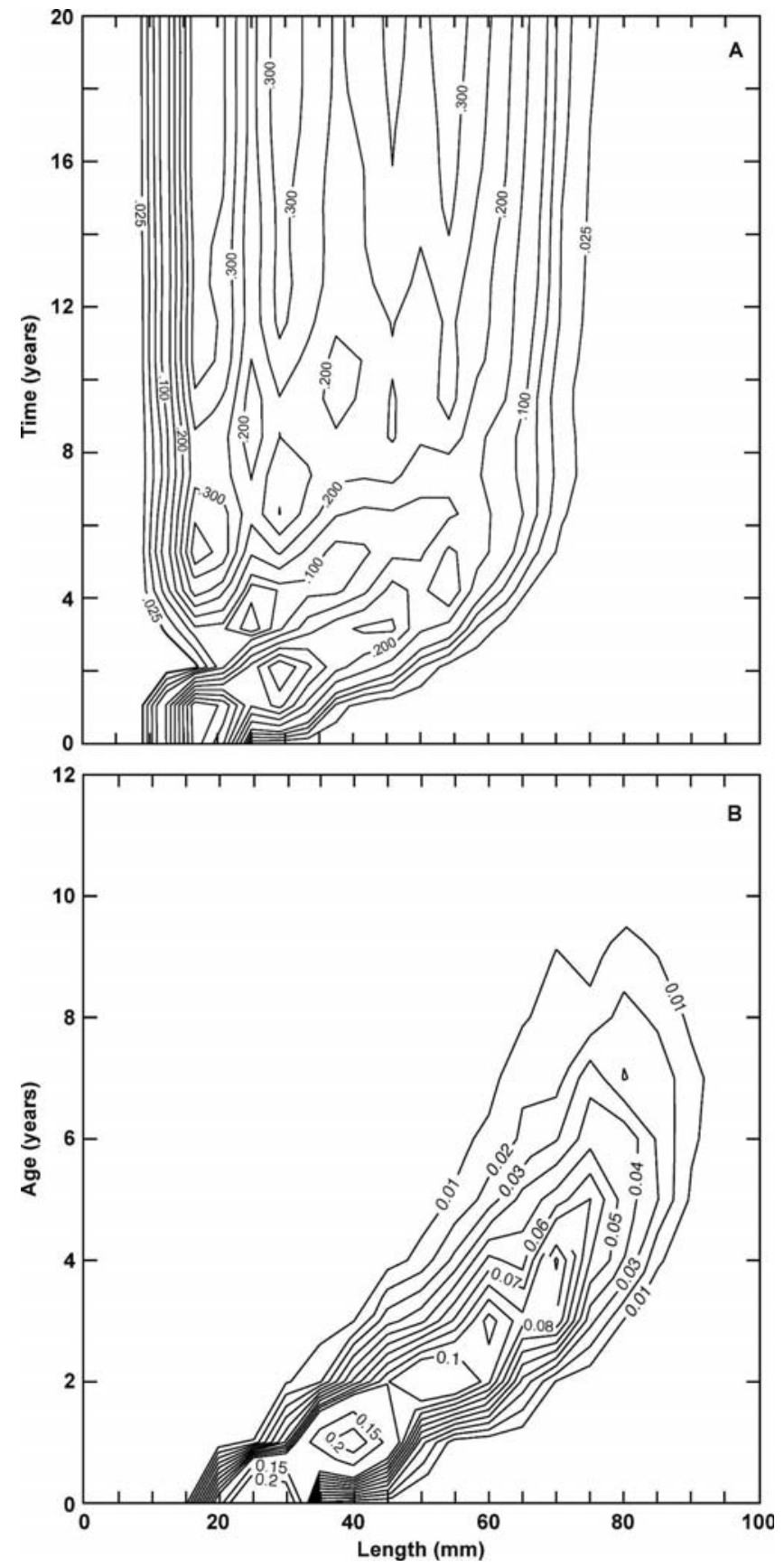

Figure 20. Simulated change in hard clam population length as a function of (A) simulation time, showing the maturity of the population length structure and (B) hard clam age, showing the age-length structure of the mature population after $20 \mathrm{y}$ of simulation time. Contours are number of individuals $\mathrm{m}^{-2}$.

Increased mortality of 60 -to-80-mm hard clams results in a population that stabilizes at a biomass and abundance (Fig. 26A) of about $1.3 \mathrm{~g}$ and 0.36 ind $\mathrm{m}^{-2}$, respectively, still well below Great South Bay observations, but higher than the 40-60 mm simulation (Fig. 24) because fecundity per $g$ dry wt is highest in clams of this latter size range and so recruitment is increased. The age-length structure of the population is truncated at lengths above $60-70 \mathrm{~mm}$ and ages in excess of simulation years 4 and 5, which correspond to clam age years of 6 and 7 (Fig. 26B). 

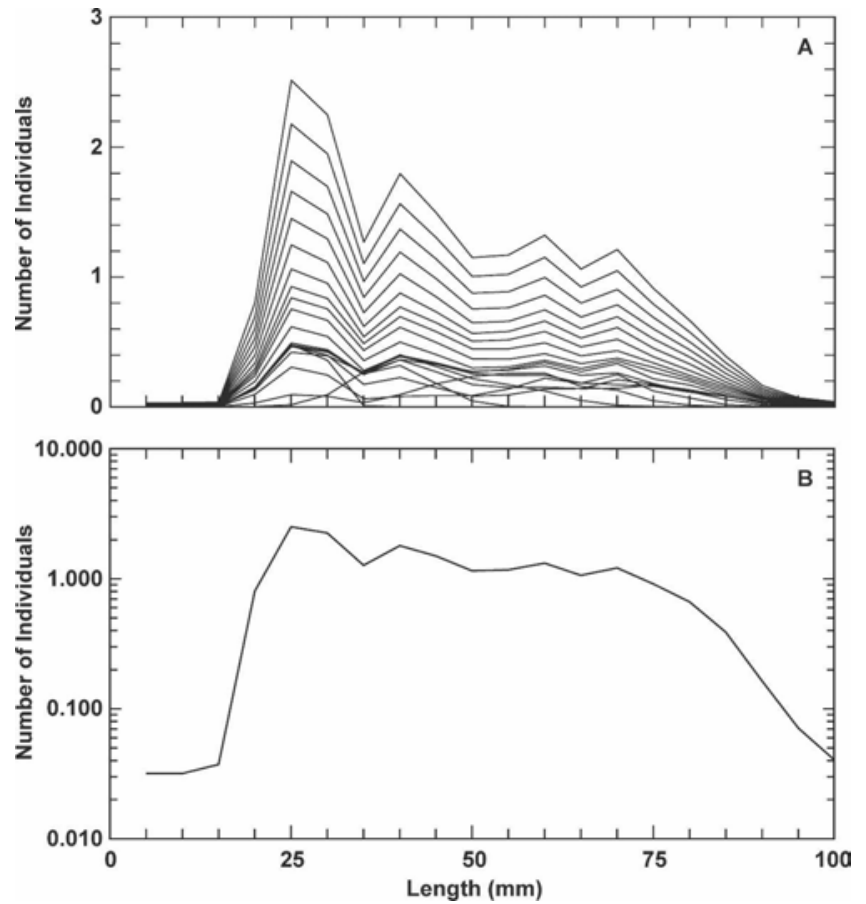

Figure 21. Simulated (A) population length frequency in which each line represents a yearly state of the population and $(B)$ the number of individuals at a given length obtained for a hard clam population in which the density-dependent constraint in the broodstock-recruitment relationship was removed.

\section{Simulated Age-length Relationships}

The age-length distribution obtained from the reference simulation (Fig. 27A) shows an almost linear relationship between length and age for hard clams between 20 and $40 \mathrm{~mm}$, after which the increase in length for an incremental increase in age slows, giving a curvature to the distribution. The upward curvature of the age-length distribution is produced by reduction in growth rate with increasing length, which is consistent with observations (e.g., Ansell 1968, Loesch \& Haven 1973, Devillers et al. 1998). Older hard clams do not increase in length as rapidly as they age. The newest two cohorts (2- and 3-y-old animals, simulation ages of 0 and $1 \mathrm{y}$ ) establish discrete modes in the population length- and age-frequency distribution; older cohorts meld into a single mode characterized by decreasing numbers as the older cohorts age (Fig. 27A).

The distribution of lengths obtained from sections across the age-length relationship at given ages produces a typical lengthfrequency diagram that becomes increasingly skewed with increasing cohort age (Fig. 27B). The tail of the distribution extends towards smaller length classes because some genotypes grow slowly and hence continually fall behind the cohort modal length. The differential growth rates of the individuals in a cohort produces, in part, the asymmetric distribution in age-length space (Fig. 27A) that is skewed towards smaller lengths and older ages. Sections through the hard clam age-length distribution at specific lengths shows that the age distribution becomes increasingly skewed at increasingly larger lengths (Fig. 27C). The long tail that extends towards older age classes occurs because the rate of natural mortality increases with clam age. The assumption that a cohort (or length class) has a Gaussian distribution of lengths (ages) is
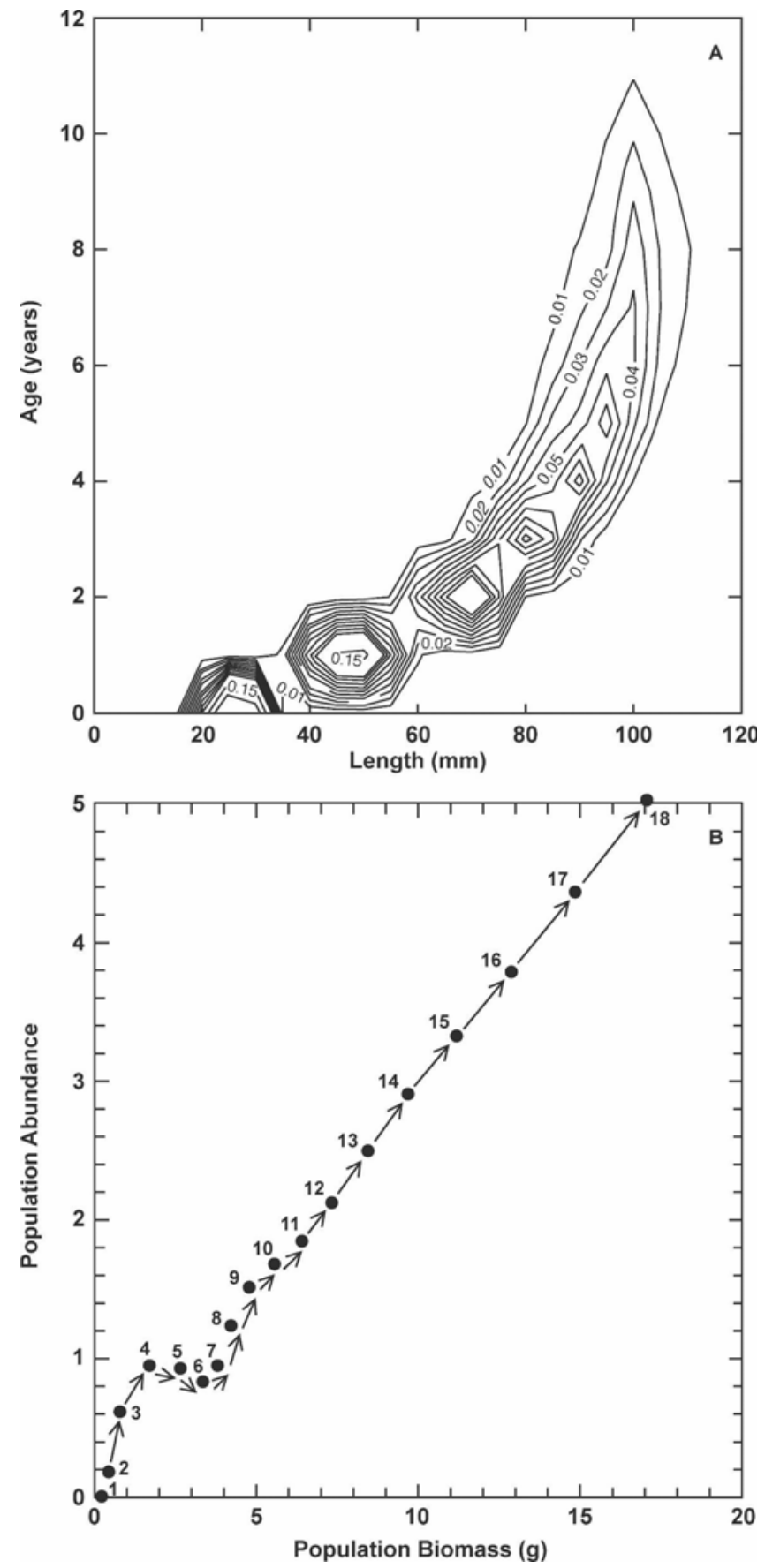

Figure 22. Simulated (A) age-length relationship and (B) the time history of population abundance as a function of biomass obtained for a hard clam population in which the density-dependence constraint in the broodstock-recruitment relationship was removed. Contours are number of individuals $\mathrm{m}^{-2}$.

correct for smaller ages (lengths) (Craig \& Oertel 1966), but the Gaussian approximation becomes increasingly less accurate at older ages and larger lengths.

The hard clam model provides a framework for ascribing causes to shape variations in age-length distributions. Variations in cohort growth rates expand (Fig. 28A) or contract (not shown) the population expression in age-length space along the long axis. Faster growth tends to maintain the Gaussian shape of the age- 

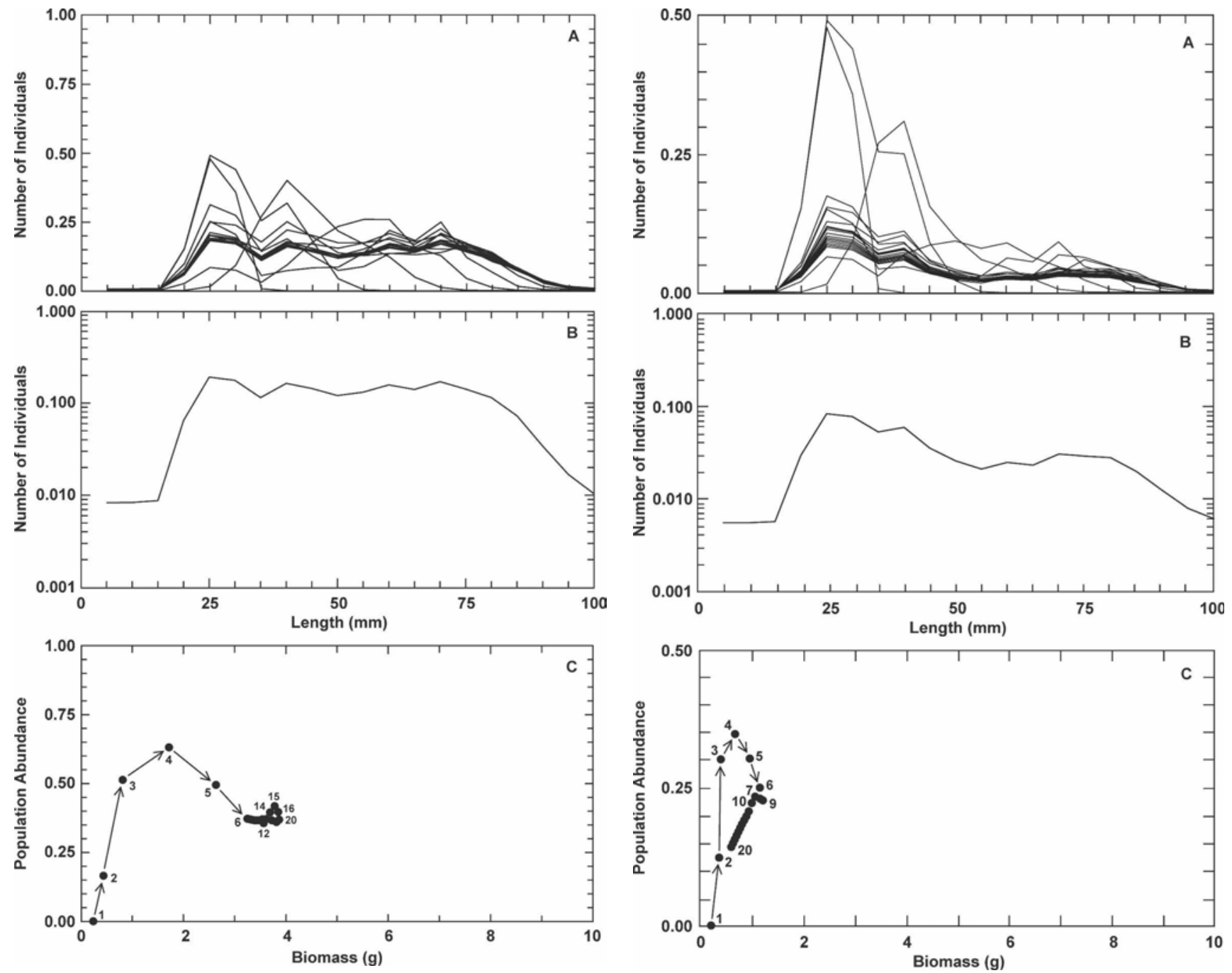

Figure 23. Simulated (A) population length frequency in which each line represents a yearly state of the population, (B) the number of individuals at a given length and $(\mathrm{C})$ the time history of population abundance as a function of biomass for a hard clam population in which the density-dependence constraint in the broodstock-recruitment relationship was increased.

frequency and length-frequency distributions (Figs. 28B, C); whereas, slow growth tends to exaggerate the asymmetry in both directions.

Decreased adult mortality rate yields an age-length distribution (Fig. 29A) that is similar to that obtained for the reference simulation (Fig. 27A). However, the asymmetry in the age-frequency distribution is greater because of the tendency for age-dependent mortality to be biased towards older ages regardless of length. A decrease in mortality rate has only a minor influence on the length frequency for a given cohort (Fig. 30A), because mortality is apportioned by cohort; that is, mortality is age-dependent rather than length dependent. In contrast, the age frequency for a given length (Fig. 30C) varies from the reference simulation. In this case, a larger fraction of animals in the larger length classes (e.g., $70 \mathrm{~mm}$ ) are represented by the oldest clams.

Increased adult mortality rate results in an age-length distribution that is compressed in age for a given length (Fig. 29B). However, the length frequency at age is similar to that from the reference simulation (Fig. 27B) and the decreased adult mortality simu-

Figure 24. Simulated (A) population length frequency in which each line represents a yearly state of the population, (B) the number of individuals at a given length and $(\mathrm{C})$ the time history of population abundance as a function of biomass for a hard clam population in which mortality imposed on the 40-to-60-mm clams was increased.

lation (Fig. 30A) because relatively more large animals are old, which truncates the length frequency at large size. The age frequency at length (Fig. 30D) is less skewed than in the reference simulation (Fig. 27C) because the older animals that add skewness to the distribution are present in much lower numbers.

Reducing recruitment by half in the last five years of the simulation narrows the age-length distribution at small length (Fig. 31A). In this simulation, a smaller fraction of the population is represented over a range of age-at-length (Fig. 31B) and lengthat-age (Fig. 31C) distributions. Relative to the reference simulation (Fig. 27B), the length frequencies of older clams are unchanged, whereas the length frequency of the 2-y-old cohort is muted by reduced recruitment. In contrast, all age frequencies are muted in comparison with the reference simulation (Fig. 27C) because some animals at nearly all lengths were $\leq 5 \mathrm{y}$ old. Hence, the distribution of age-at-length has been affected more than the distribution of length-at-age.

The shape of the hard clam population age-length distribution is also controlled by the cohort genetic composition. A restricted 


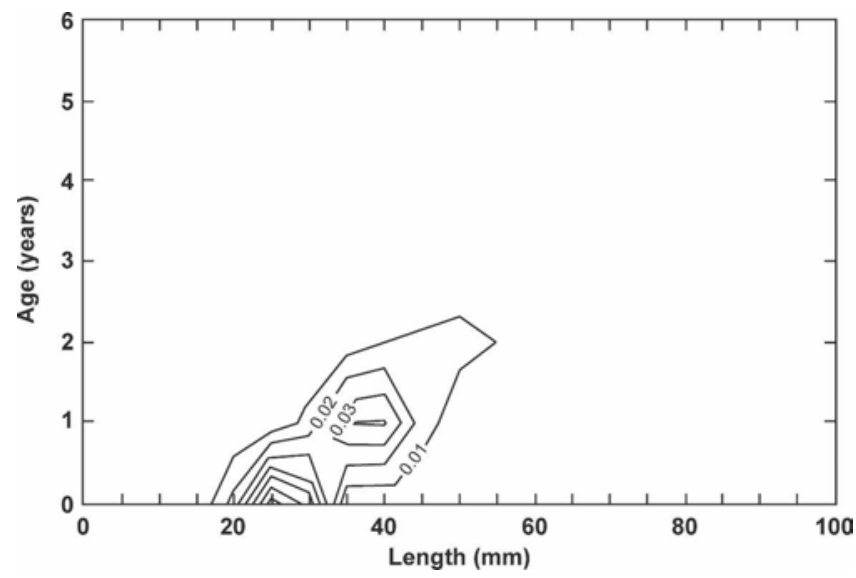

Figure 25. Simulated age-length relationship for a hard clam population in which mortality imposed on the 40-to-60-mm clams was increased. Contours are number of individuals $\mathbf{m}^{-2}$.

proportion of slow and fast growers in the cohort, which reflects numerical abundance of a narrow range of genotypes, yields a markedly different population structure (Fig. 32A). This agelength composition is similar to that obtained with increased
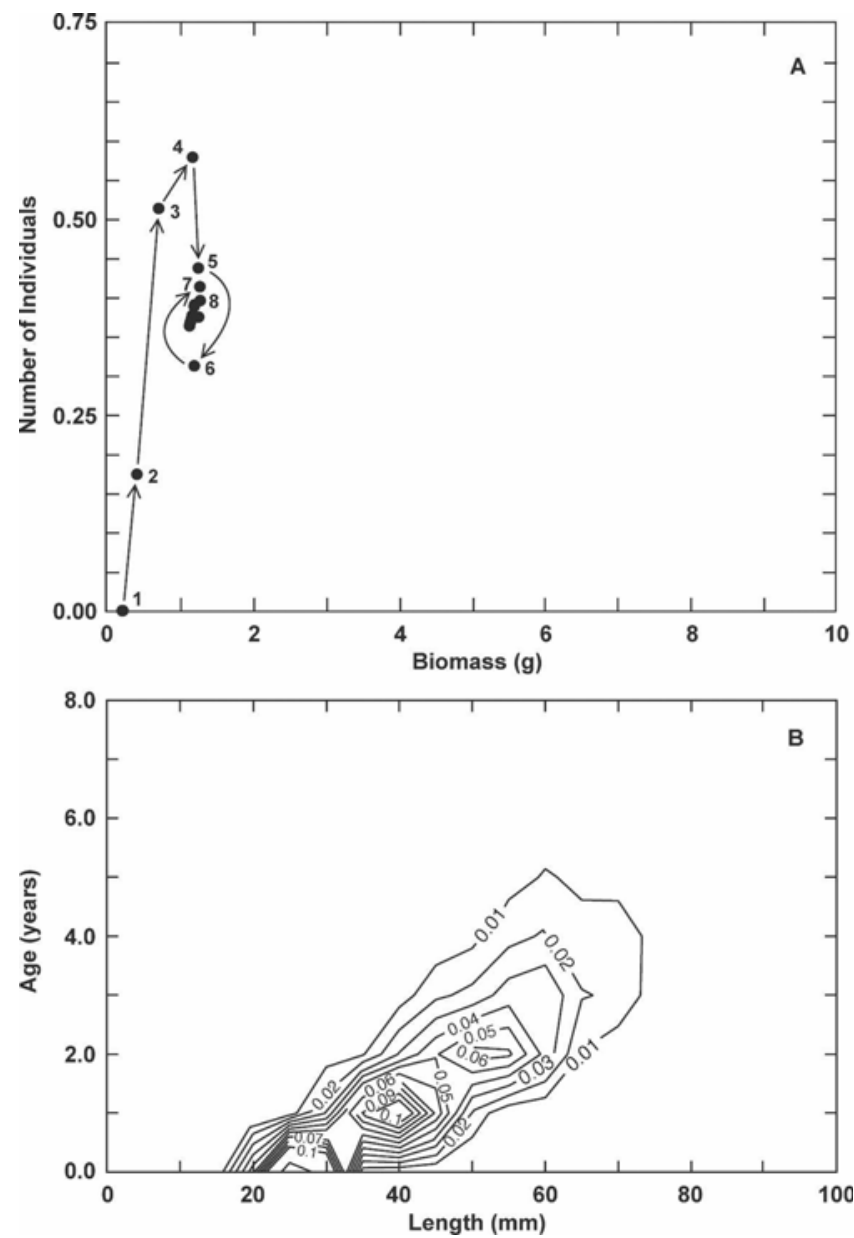

Figure 26. Simulated (A) time history of population abundance as a function of biomass and (B) age-length relationship for a hard clam population in which mortality imposed on the $60-$ to- $80-\mathrm{mm}$ clams was increased.
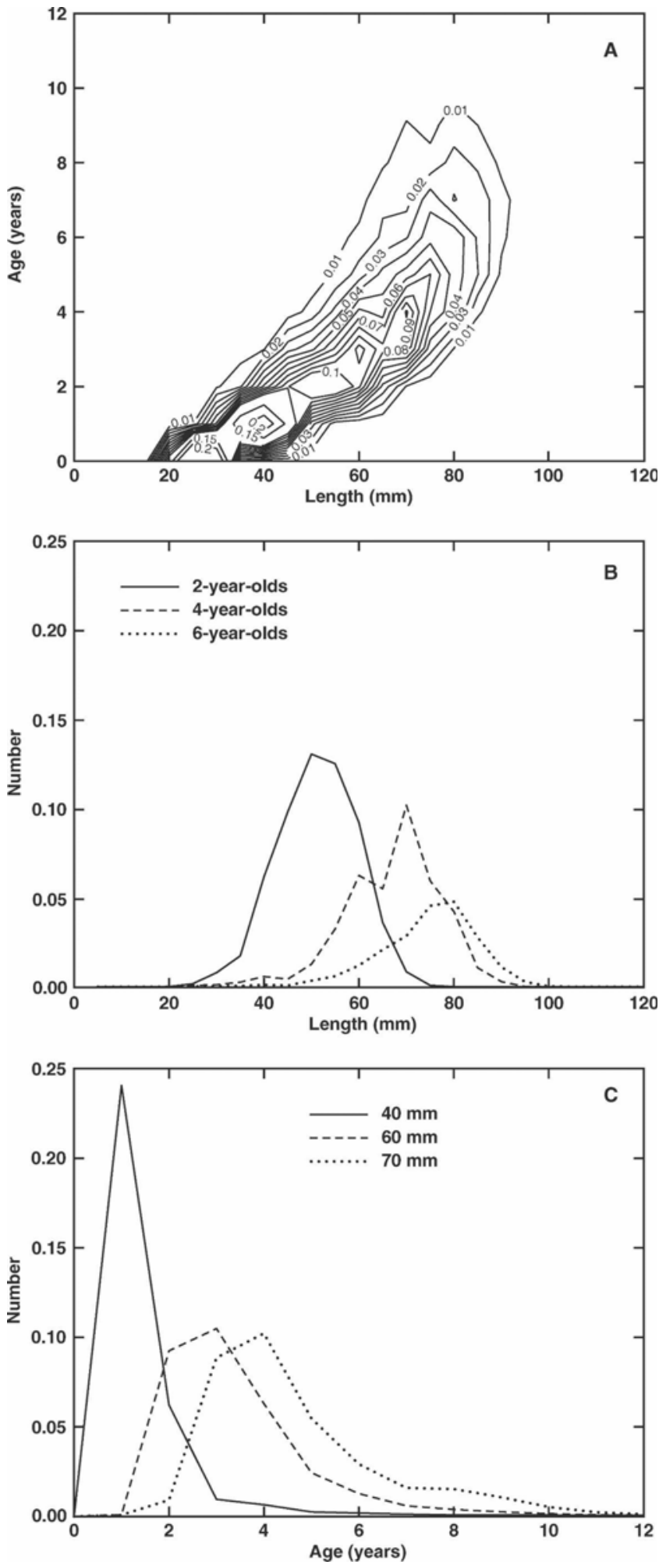

Figure 27. Simulated (A) age-length (B) length-at-age and (C) age-atlength frequency distributions obtained from the reference simulation that used standard environmental conditions for Great South Bay, NY. Contours are number of individuals $\mathbf{m}^{-2}$.

growth rate (Fig. 28). The degree of bending along the long axis is increased with respect to the reference simulation (Fig. 27A) because more individuals in the cohort have the average genotype and this also constrains the width of the age-length distribution in 

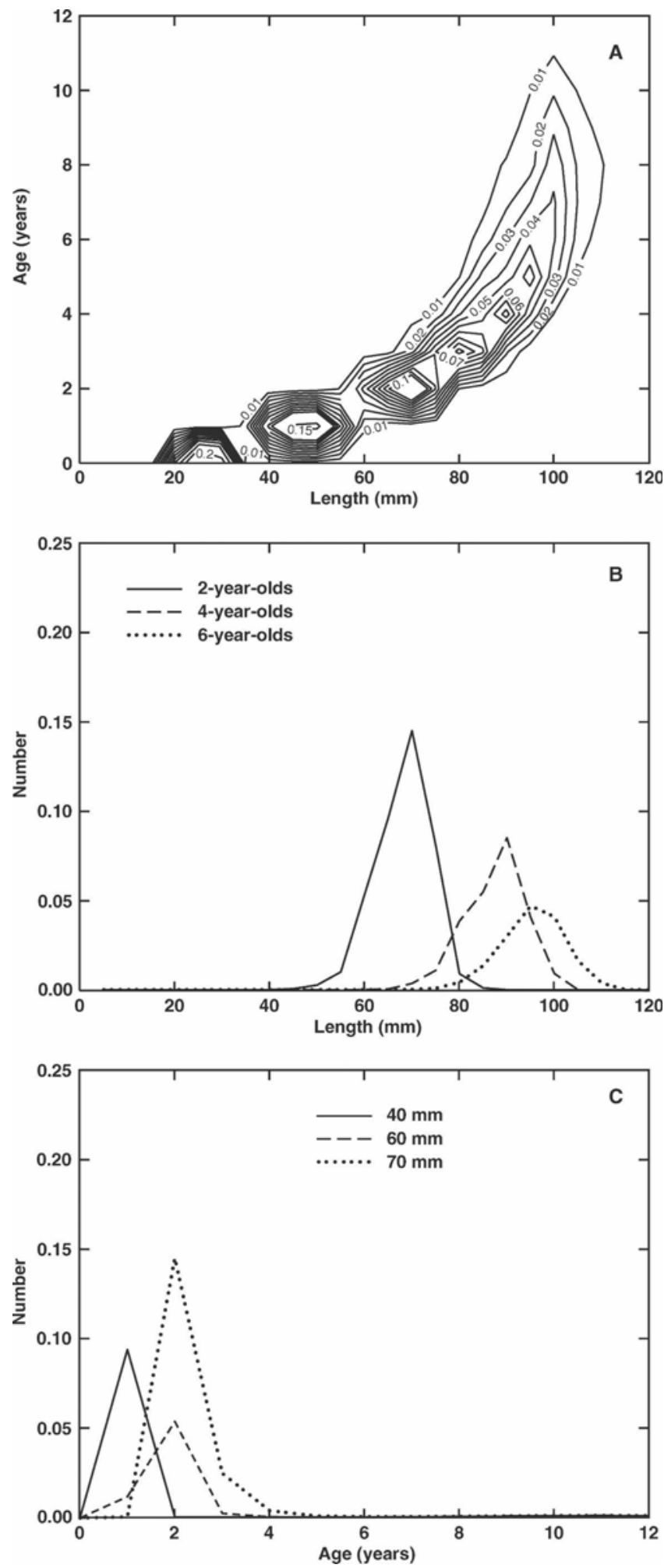

Figure 28. Simulated (A) age-length (B) length-at-age and (C) age-atlength frequency distributions obtained when the population growth rate is increased. Contours are number of individuals $\mathbf{m}^{-2}$.

age-length space. The range of lengths at age is small, as is the range of ages at length. Because the increase in length ceases relatively uniformly within the cohort, the increment in age for a given increment in length increases with age, producing a strongly curved age-length distribution.
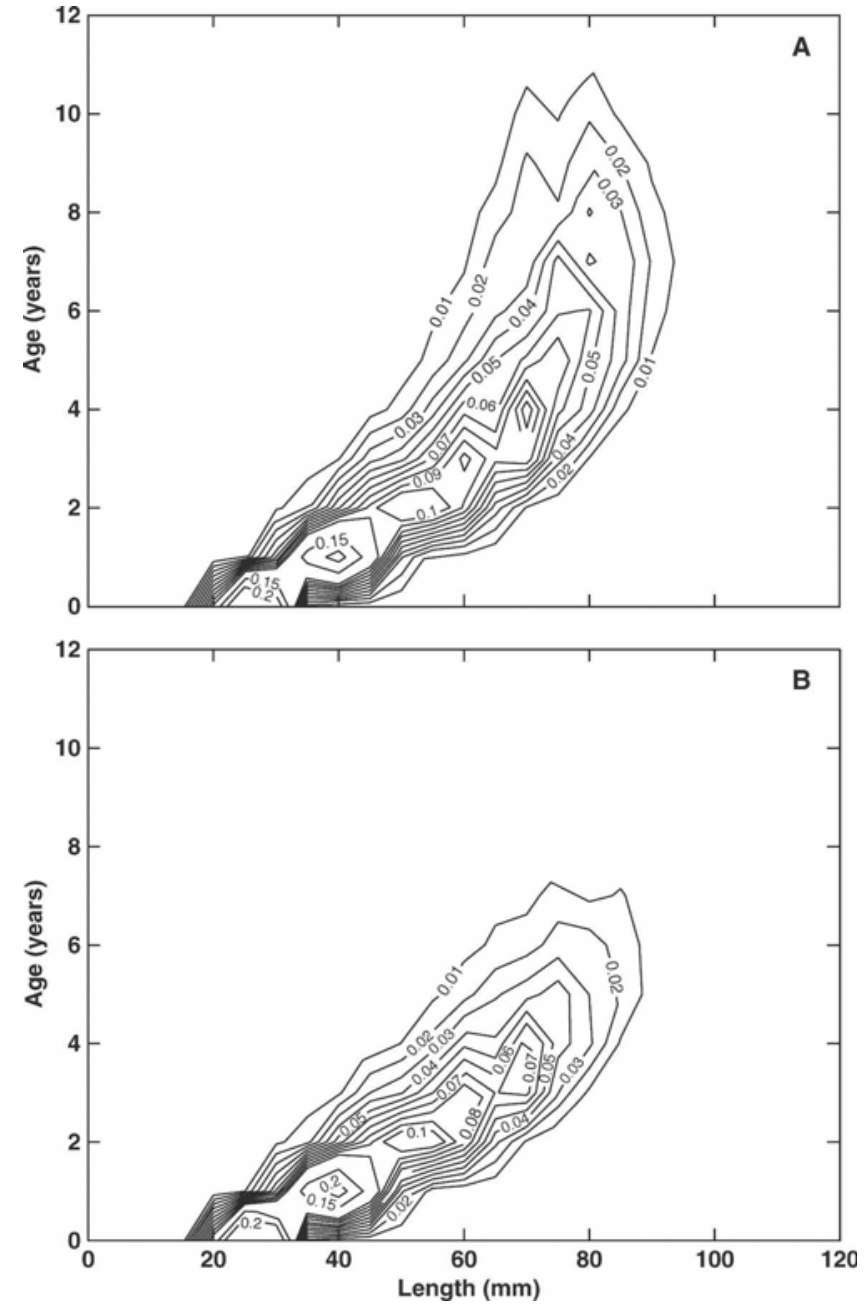

Figure 29. Simulated age-length distributions obtained when adult mortality rate is A) decreased and B) increased. Contours are number of individuals $\mathrm{m}^{-2}$.

An expanded proportion of slow and fast growers in the cohort, which provides more even representation of genotypes, substantially changes the appearance of the hard clam population (Fig. 32B). The degree of bending along the long axis is lessened because more individuals in the cohort grow faster at older age. However, more individuals in the cohort also grow slower at older ages. As a consequence, the age-length distribution expands along both axes. The range of lengths at age is wider, as is the range of ages at length. These two trends straighten the shape of the population structure in age-length space, but also truncate the length of the long axis because fewer very-old and very-large animals exist.

\section{Development of General Age-length Relationship}

The age-length distributions obtained from the simulated populations (Figs. 27, 28, 30, 31, 32) have common characteristics. Each is inclined at an angle to the age-length axes, the long axis typically twists upwards, and the asymmetry along the long axis typically increases with progression towards older, larger clams. The asymmetry in these age-length distributions is internally consistent in that a more restricted length and age range of clams falls on the younger and larger side of the long-axis ridge. The curvature in the location of the ridge as the clams get older indicates that a maximum length exists for the population and that older clams 

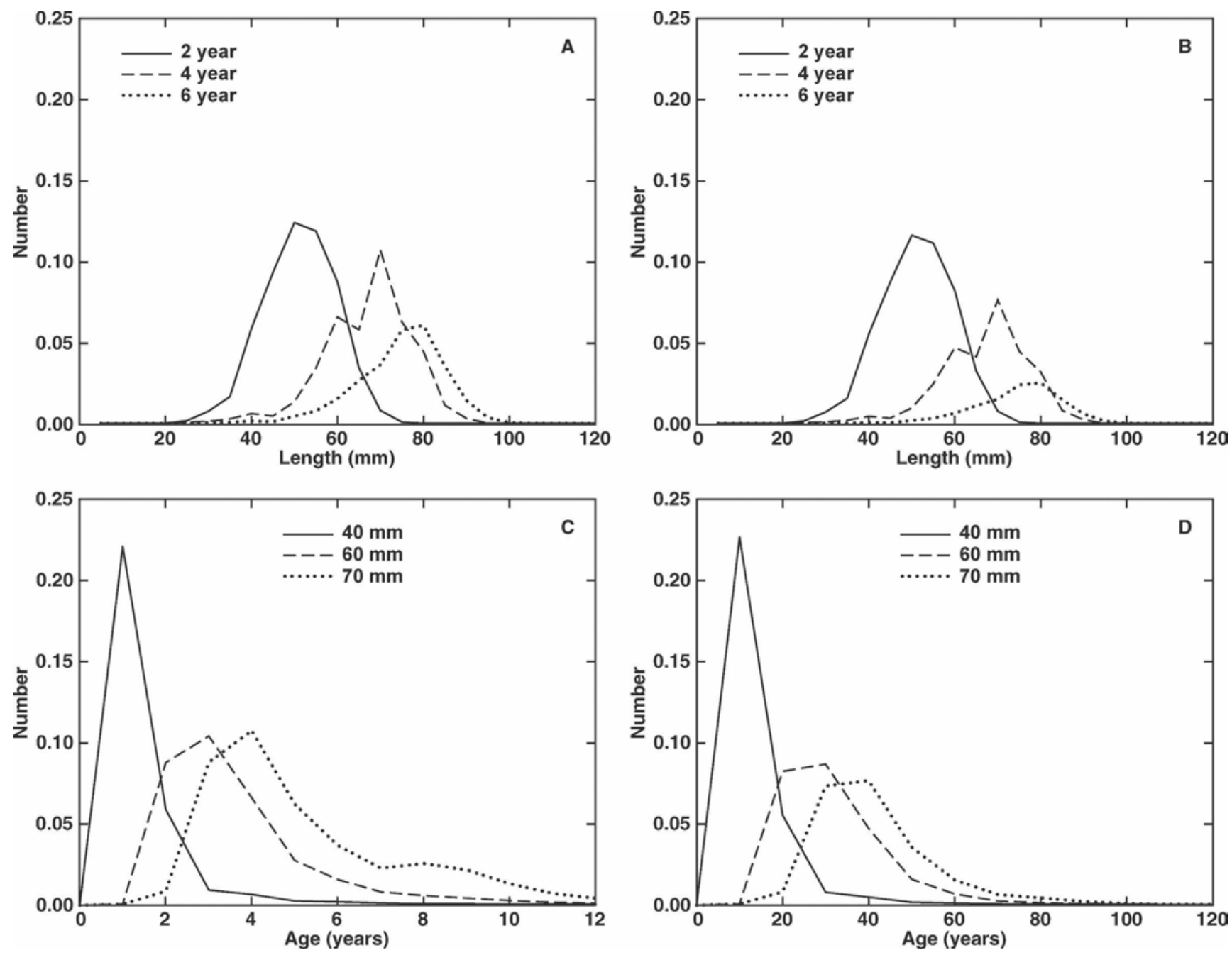

Figure 30. Simulated age-at-length obtained for (A) decreased and (B) increased adult mortality rate and simulated length-at-age obtained for (C) decreased and (D) increased adult mortality.

live for a while near their largest length. The age-at-length and length-at-age slices through the various age-length relationships show that these follow an approximate Gaussian distribution (e.g., Fig. 30). The similarity in the form of the various age-length distributions obtained from simulations that included a range of different processes suggests that they can be described by a general mathematical relationship, as developed in the following sections.

\section{Formulation of a Twisted Bivariate Gaussian Functional Form}

The structure of the age-length relationship can be reproduced by a bivariate Gaussian function that includes the capabilities for curvature at increasing age and length and for variability in the distribution about a given age or length. The bivariate Gaussian function was implemented in atated coordinate system $(x, y)$ that is aligned along the axis of the maximum in the length-age $(L, A)$ distribution in the original coordinate system (Fig. 33). The alignment is done using a coordinate rotation angle $\theta$, which shifts the new coordinate system counterclockwise relative to the age axis. The rotated coordinate system is centered around a central age $\left(A_{o}\right)$ and length $\left(L_{o}\right)$ that are representative values associated with the maximum in the age-length distribution. These parameters control the location of the origin of the rotated coordinate system relative to the original age-length distribution. The $x$ and $y$ axes in the rotated coordinate system are scaled by the factors $S_{A}$ and $S_{L}$, which allows matching of the magnitude of the age and length values in the two coordinate systems. The coordinate transformation is:

$$
\left(\begin{array}{l}
x \\
y
\end{array}\right)=\left(\begin{array}{cc}
\cos \theta & \sin \theta \\
-\sin \theta & \cos \theta
\end{array}\right) \cdot\left(\begin{array}{l}
S_{L}\left(L-L_{o}\right) \\
S_{A}\left(A-A_{o}\right)
\end{array}\right)
$$

and the correspondence between the original age-length coordinate system and the rotated coordinate system is shown in Figure 33.

The transformed coordinate system aligns the age-length distribution so that it can be fit with a bivariate Gaussian function to obtain the number of individuals $\mathrm{m}^{-2}$ at a given length and age, $N$ $(x, y)$, as:

$$
N(x, y)=N_{0} e^{\frac{-x^{2}}{2 \sigma_{x}^{2}}} e^{\frac{-\left(y-y_{m}\right)^{2}}{2 \sigma_{y}^{2}}}
$$

where $N_{0}$ is the maximum number of individuals $\mathrm{m}^{-2}$ at zero age, $x$ and $y$ are the transformed length and age axes, respectively, and $\sigma_{x}$ and $\sigma_{y}$ determine the spread of the Gaussian, the standard deviation, along the length and age distribution, respectively. The 

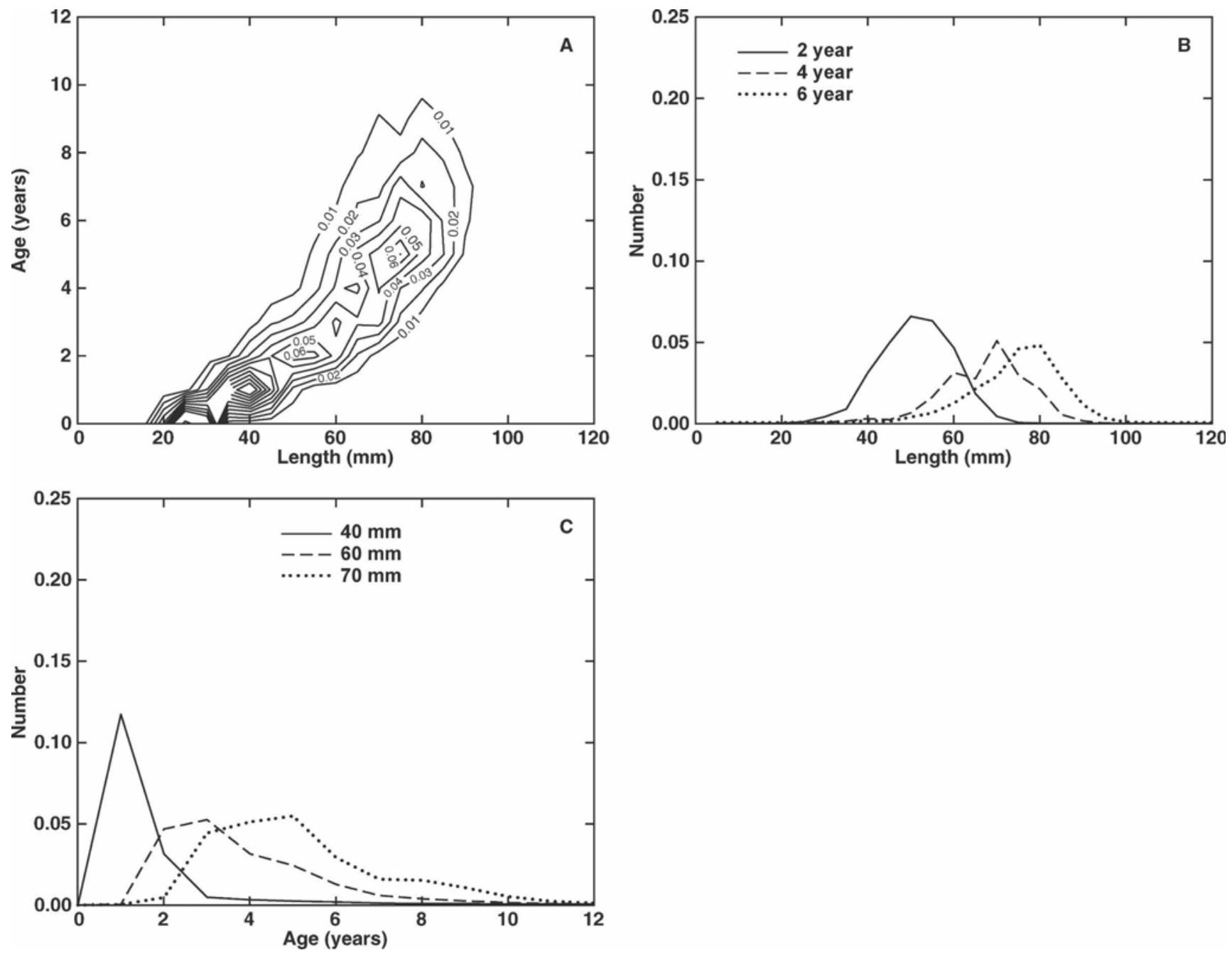

Figure 31. Simulated (A) age-length (B) length-at-age and (C) age-at-length frequency distributions obtained when the recruitment rate is decreased. Contours are number of individuals $\mathbf{m}^{-2}$.

parameter $y_{m}$ is the center of the Gaussian distribution along the rotated age axis $(y)$.

The typical age-length distribution (e.g., Fig. 27A) has three additional features that need to be included in Eq. (32). First, the ridge in age-length space curves upward for older and longer clams. The curvature of the age-length distribution at older and longer clams is introduced by allowing the center of the Gaussian distribution, given by $y_{m}$, to change as a function of the rotated $x$ coordinate:

$$
y_{m}=a x^{n}
$$

which shifts the centroid of the Gaussian towards positive $y$ with increasing $x$, with the degree of curvature determined by $n$ (Fig. 33). This modification to $y_{m}$ provides the twist to the bivariate Gaussian.

Second, the age-length distribution has a shallower slope (is wider) for older (longer) clams relative to younger (shorter) clams, which produces an asymmetric distribution. The asymmetry in the spreading of the age-length distribution about the maximum ridge value is created by allowing $\sigma_{y}$ to vary along the rotated age axis $(y)$.

Third, the width of the age-length relationship increases for older and longer clams. The spreading of the age-length distribu- tion for older and longer clams is created by increasing the value of $\sigma_{y}$ with distance along the rotated length axis, $x$, as:

$$
\sigma_{y}(x, y)=\left\{\begin{array}{l}
S 1(1+b 1 x), \text { if } y-y_{m}>0 \\
S 2(1+b 2 x), \text { if } y-y_{m}<0
\end{array}\right.
$$

where the parameters $S 1, S 2, b 1$ and $b 2$ are obtained from fitting the general age-length relationship to an age-length data set, as described in the following section. This modification allows $\sigma_{y}(x$, $y$ ) to have different values on either side of the maximum ridge value, $y_{m}$.

The addition of the above modifications to Eq. (32) gives a twisted bivariate Gaussian of the form:

$$
N(x, y)=N_{o} e^{\frac{-x^{2}}{2 \sigma_{x}^{2}}} e^{\frac{-\left(y-y_{m}(x)\right)^{2}}{2 \sigma_{y}(x, y)^{2}}}
$$

The application of Eq. (35) to determine age-length distributions is described in the following section.

\section{Functional Fitting Procedure}

The twisted bivariate Gaussian function (Eq. 35) has 13 parameters that need to be specified to create an age-length distribution. The coordinate scaling factors $\left(S_{L}, S_{A}\right)$ and the Gaussian width in the same direction $\left(\sigma_{x}, \sigma_{y}\right)$ are not independent param- 

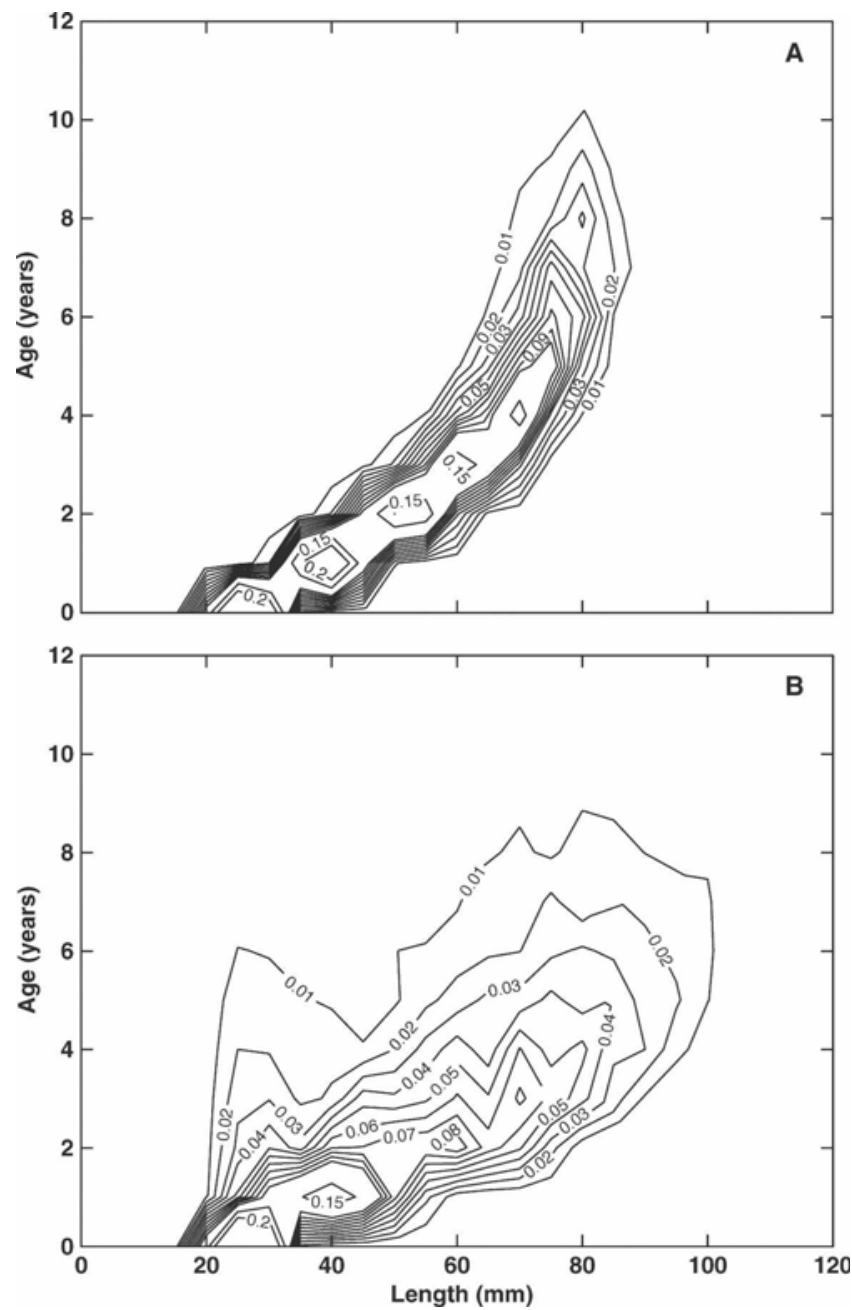

Figure 32. Simulated age-length frequency distributions obtained when the range of assimilation efficiency genotypes was (A) narrower and (B) broader in comparison with the reference simulations. Contours are number of individuals $\mathbf{m}^{-2}$.

eters, so the values of $S_{L}$ and $S_{A}$ were specified and the Gaussian width parameters were determined. The rotated $(x, y)$ coordinate system is constrained to be on the $A=0$ axis by choosing $A_{o}=$ 0 . The remaining 10 parameters (Table 4 ) need to be determined.

The parameter fitting procedure is based on minimizing the difference in hard clam age-length distributions obtained from observations and those obtained from the twisted bivariate Gaussian model (Eq. 35). Prior to the start of this procedure, the age-length data sets were filtered relative to a threshold value because many age-length combinations do not occur in hard clam populations. These combinations were removed from the input data sets by setting a minimum length criterion for each age-length combination. For this study, the maximum clam density in the simulated age-length distributions, which is controlled by the total number of clams in the population model, is 0.25 clams of a given age and length $\mathrm{m}^{-2}$. The threshold value for the age-length distributions was set at $6 \%$ of this maximum value, 0.015 clams $\mathrm{m}^{-2}$.

The parameter fitting procedure is based on minimizing the sum square deviation between the observed number of clams $\mathrm{m}^{-2}$ $\left(N_{i}{ }^{o}\right)$ and the theoretically-derived number of clams $\mathrm{m}^{-2}\left(N_{i}^{f}\right.$, obtained from Eq. 35) for a given length $\left(L_{i}\right)$ and age $\left(A_{i}\right)$ as:

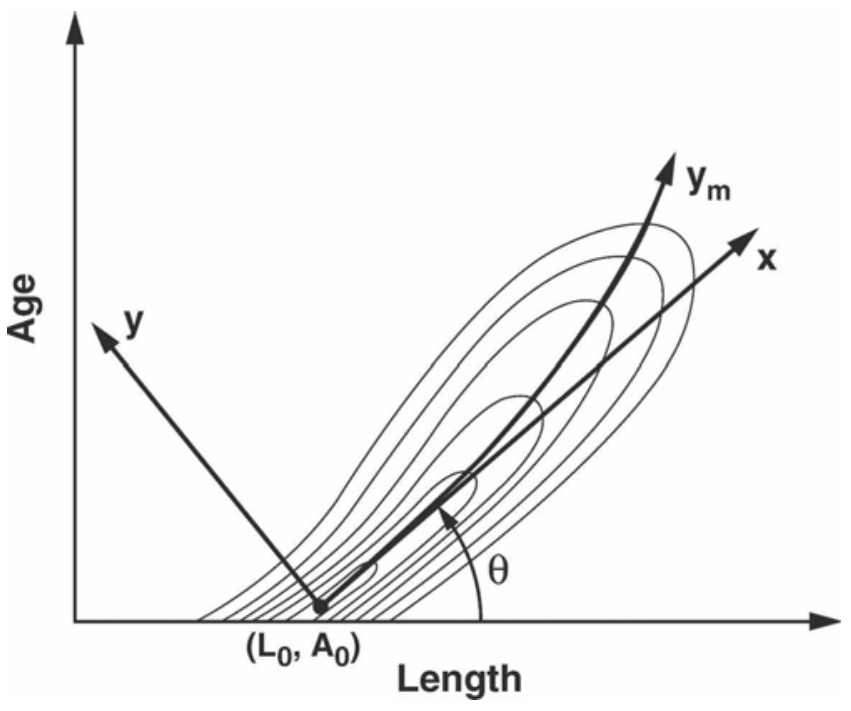

Figure 33. Schematic of correspondence between the age-length coordinate system and the scaled age-length coordinate system used for the twisted bivariate Gaussian function. The axes $(x, y)$ of the scaled coordinate system have an origin at $\left(L_{0}, A_{0}\right)$ and are rotated relative to the original length and age axes by the angle $\theta$. The curvature of the age-length distribution is given by $y_{m}$. See text for additional details of the scaled age-length coordinate system.

$$
C=\sum_{i}\left(N_{i}^{o}-N_{i}^{f}\right)^{2},
$$

where $C$ is a measure of the misfit between the observed and theoretical age-length distributions.

The minimization procedure is most efficient when started with initial parameter values that are near optimal values. The initial parameter values were estimated by an iterative procedure in which the minimum and maximum values for a particular parameter were used to set a range for the parameter. Values at $25 \%$, $50 \%$ (midpoint) and $75 \%$ of this range were then determined and these along with the two extremes were used in Eq. (35) and the misfit between the theoretical and observed age-length distribution was determined with Eq. (36). The parameter set that produced the minimum misfit was taken as the initial parameter values and the minimization procedure repeated to yield a second estimate of the optimal parameter set. This parameter set was then used as initial values and the minimization procedure repeated a third time. The parameter values that were obtained from this minimization provide the starting point for a multidimensional minimization procedure, based on Powell's Method (Press et al. 1989), which produces the final optimal parameter set. This final parameter set provides the best fit of the twisted bivariate Gaussian model to a particular age-length data set. Once the optimal parameter set is determined, the twisted bivariate Gaussian model can be used to develop an age-length distribution that includes all ages and lengths.

\section{Parameterization of Simulated Age-length Relationships}

The age-length data sets obtained from the simulations in which growth, mortality and recruitment rates were varied, and in which the apportionment of individuals among genotypes was expanded and reduced, were used to fit the 10 free parameters for the twisted bivariate Gaussian function (Table 4). The resulting parameters were then used with Eq. (35) to produce age-length distributions (Fig. 34). 
TABLE 4.

Optimal parameter values obtained from fitting the twisted bivariate Gaussian given by eq. (35) to different simulated hard clam population age-length data sets. The figure showing the corresponding age-length distributions is indicated.

\begin{tabular}{|c|c|c|c|c|c|c|c|c|}
\hline & $\begin{array}{c}\text { Reference } \\
\text { Case }\end{array}$ & $\begin{array}{c}\text { Decreased } \\
\text { Growth }\end{array}$ & $\begin{array}{c}\text { Increased } \\
\text { Growth }\end{array}$ & $\frac{\text { Increased }}{\text { Adult Mortality }}$ & $\frac{\text { Decreased }}{\text { Adult Mortality }}$ & $\begin{array}{c}\text { Decreased } \\
\text { Recruitment }\end{array}$ & $\begin{array}{l}\text { Reduced } \\
\text { Genetics }\end{array}$ & $\begin{array}{c}\text { Expanded } \\
\text { Genetics }\end{array}$ \\
\hline$L_{0}$ & 27.5 & 25.2 & 29.9 & 25.0 & 26.9 & 28.2 & 27.6 & 21.8 \\
\hline$\theta$ & 0.550 & 0.879 & 0.260 & 0.553 & 0.490 & 0.551 & 0.414 & 0.258 \\
\hline$a$ & 0.0333 & -0.0055 & 0.0074 & 0.0198 & 0.0501 & 0.0361 & 0.0778 & 0.0401 \\
\hline$n$ & 2 & 2 & 3 & 2 & 2 & 2 & 2 & 2 \\
\hline$S 1$ & 0.322 & 0.312 & 0.366 & 0.197 & 0.361 & 0.390 & 0.352 & 0.637 \\
\hline$b 1$ & 0.158 & 0.155 & 0.111 & 0.158 & 0.158 & 0.158 & 0.044 & 0.355 \\
\hline$S 2$ & 0.235 & 0.479 & 0.519 & 0.322 & 0.322 & 0.176 & 0.152 & 0.511 \\
\hline$b 2$ & 0.080 & 0.022 & -0.155 & 0.041 & 0.100 & 0.080 & 0.102 & -0.199 \\
\hline $\mathrm{N}_{0}$ & 0.183 & 0.078 & 0.172 & 0.201 & 0.151 & 0.083 & 0.283 & 0.178 \\
\hline$\sigma_{x}$ & 4.46 & 3.36 & 5.17 & 3.83 & 5.09 & 6.00 & 4.18 & 4.00 \\
\hline Figure No. & $27 \mathrm{~A}$ & not shown & $28 \mathrm{~A}$ & $29 \mathrm{~B}$ & $29 \mathrm{~A}$ & $31 \mathrm{~A}$ & $32 \mathrm{~A}$ & $32 \mathrm{~B}$ \\
\hline
\end{tabular}
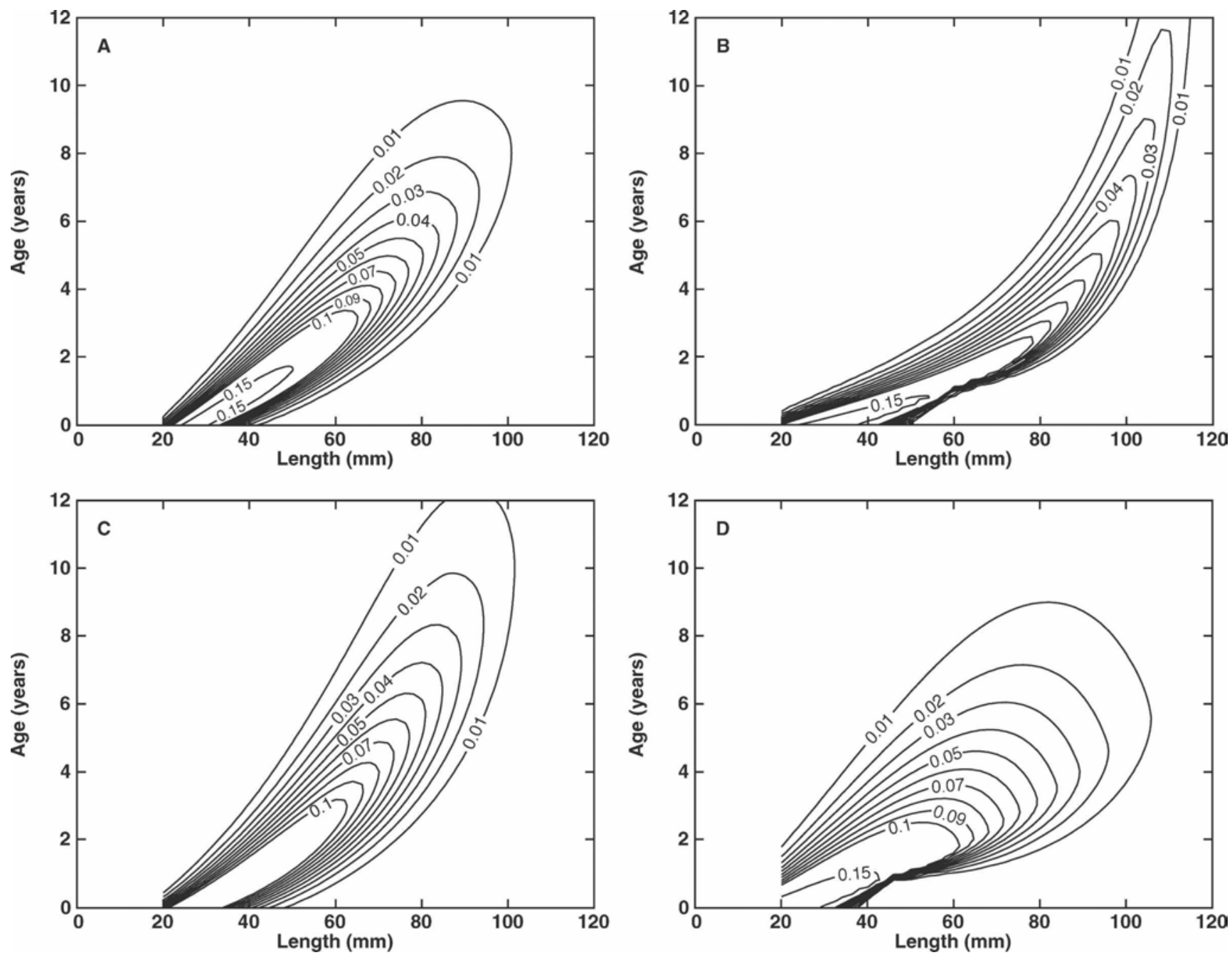

Figure 34. Age-length distributions obtained by fitting the twisted bivariate Gaussian formulation (Eq. 35) to the simulated age-length data sets obtained for a hard clam population in Great South Bay for: (A) the reference simulation, (B) increased growth rate, (C) decreased adult mortality rate and (D) even apportionment of genotypes, obtained by setting $\sigma_{C 1}$ and $\sigma_{C 2}$ in Eq. 17 equal to 0.25. Contours are number of individuals $\mathrm{m}^{-2}$. The parameter values obtained from fitting the twisted bivariate Gaussian to the different simulated hard clam age-length data sets are given in Table 4. 
The simulated age-length data sets produced with decreased growth rate, increased adult mortality, decreased adult mortality, and expanded genetic range resulted in optimal values for the central length $\left(L_{o}\right)$ that are smaller than that obtained for the reference simulation age-length data set (Table 4). The value of $L_{0}$ determines where the $x$-axis of the rotated coordinate system intersects the length axis in the original coordinate system (Figs. 33 and 34). The value of this parameter indicates that the small animals have a smaller average size in these simulations than those in the age-length distributions obtained from the reference simulation. The age-length data sets from the increased growth-rate, reduced genetic range and decreased recruitment rate simulations gave an optimal $L_{0}$ that is larger than the value obtained from the reference simulation. This indicates that the small animals in these simulations are on average larger than those in the reference simulation.

The age-length distribution created by decreased growth rate yields values for $L_{\mathrm{o}}, a, \sigma_{x}$ and $b 2$ that are reduced relative to the values obtained from the reference simulation (Table 4). The parameter $\theta$ is unusually high. The parameters $\sigma_{x}$ and $b 2$ produce greater asymmetry in the length and age-frequency distributions, which skews these distributions towards smaller lengths and older ages. These characteristics are consistent with a slow growing hard clam population. The negative value for $a$ indicates a tendency for old animals to grow slower at a given length and the high value of $\theta$ shows that age increases relatively rapidly for an increase in length. Collectively, no other simulated condition has values of $L_{\mathrm{o}}$, $a, \sigma_{x}$ and $b 2$ simultaneously this low and $\theta$ this high.

Increased growth rate creates a simulated hard clam population with an age-length distribution that is characterized by a combination of high $L_{\mathrm{o}}, S 2$ and $\sigma_{x}$ and low values for $\theta, a$ and negative $b 2$. These parameters result in a narrow, elongated age-length distribution that intersects the length axis at a small angle (Fig. 28A). The curvature of the age-length distribution produced with increased growth rate is more pronounced than that from other simulations and as a result, the parameter $(n)$ determining the curvature of $y_{m}$ differs from the parabolic dependence obtained for the reference simulation and all other cases (Table 4). No other simulation has this unique set of parameters, the low values of $b 2$ and $a$ being particularly noteworthy.

A decrease in adult mortality yields high $a, \sigma_{x}$ and $b 2$ values, which produce an age-length distribution that has more curvature in the long axis and increased spread in age for a given length (Fig. 29A). The high value of $\sigma_{x}$ distinguishes this simulation from another simulation with high $a$ and $b 2$ values, the simulation of a decreased range of genotypes (Fig. 32A), and this can be observed in Figure 29A by the broader range of values on the rotated $\mathrm{x}$-axis of this simulation. Increased adult morality (Fig. 29B) results in an age-length distribution with low $\sigma_{x}$ and $S 1$ values (Table 4). This combination of parameters gives an age-length distribution that is less spread out about the rotated $y$-axis and the rotated $x$-axis than the distributions produced by other parameter combinations.

The parameter fits from the simulation with lower recruitment in the last five years of the simulation (Fig. 31A) yield a lower value of $S 2$ and an exceptionally high value of $\sigma_{x}$ relative to the reference simulation (Table 4 ). These parameters control the spread of the Gaussian about the rotated $x$-axis and reduce the asymmetry about the y-axis. The narrowing of the age-length distribution at small length is an expression of this parameterization.

Increasing the relative abundance of slow and fast growing clams to the composition of the cohort, by increasing the evenness of the distribution of genotypes in the cohort, modifies all of the parameters that control the spread of the age-length distribution about the long axis (Table 4). This combination of parameters gives an age-length distribution that is straighter and spreads out asymmetrically at older age and longer lengths (Fig. 32B). Reducing the distribution of genotypes in a cohort again modifies the optimal parameter set (Table 4) and produces an age-length distribution that is narrow and symmetric with age and length (Fig. $32 \mathrm{~A}$ ). Note the unusually low values of $b 1$ and $\sigma_{x}$ is unusually low for both of these genotype modifications, indicating the increased uniformity in cohort composition, caused in one case by the increase in abundance of genotypes rare in the reference simulation and the other by the decrease in abundance of the same genotypes.

\section{DISCUSSION}

\section{Formulation of Model Processes}

The hard clam simulations provide guidance for future research topics because formulations used for some processes included in the model differ from those routinely used in population dynamics models. Hard clam mortality was assumed to be age, not length, dependent. The filtration rate parameterization provides an asymmetric increase with increasing temperature up to a specified temperature, after which it declines sharply. These parameterizations were needed to obtain simulated growth rates for individual hard clams that matched observed rates.

Additional assumptions were made that affect the simulated cohort and population structure. These include parameterizations that limit fecundity as individual clam length increases and impose a temperature- and time-dependent control on the reproductive cycle. The concept of quality days was used to terminate hard clam reproduction so that the duration of the simulated reproductive cycle and egg production matched observations. That hard clam reproduction does cease in the fall is known. However, the basic physiological processes that result in cessation of reproduction are not known. This is one area highlighted by the model development where more research is needed.

The form of the broodstock-recruitment relationship places a strong constraint on how the cohorts are concatenated to form a population. The form chosen for this study is one of many possible approaches (Kraeuter et al. 2005). Specification of the appropriate form requires continued and long-term monitoring of hard clam populations.

The simulations show that chlorophyll $a$ alone is not adequate to support hard clam growth, which is consistent with results from models developed for other shellfish (Soniat et al. 1998, Hyun et al. 2001). Comparisons with observations from Great South Bay show that the hard clam growth form (e.g., timing and rate of growth) is not adequately simulated by a chlorophyll-only food source, implying that alternative food sources are being used. This required that the food supply input to the model be modified to allow for nonchlorophyll food sources (cf. Fig. 9D). The nature and magnitude of the alternative food sources needed by hard clams is deserving of investigation and may be an important component of hard clam restoration efforts.

The individual-based hard clam model was developed for Great South Bay where salinity and turbidity variations are small and do not typically extend into ranges that inhibit metabolic processes. Application of the hard clam model to environments characterized by lower salinity or higher total suspended solid concentrations than are typical for Great South Bay requires further verification studies. In particular, little experimental data exist on the effects of salinity and its interaction with temperature and total suspended solids on hard clam physiology and metabolism. 


\section{Generalized Age-length Relationship}

In individual shellfish, growth in age and length is partially decoupled. Growth rates within a cohort are such that many animals of differing ages may have the same length and many animals of differing length may have the same age. The age-length structure of a population is determined by a finite number of processes that control cohort length frequency, such as growth rate (Craig \& Oertel 1966) and mortality rate, either of which may be age- or length-dependent. A small number of growth models routinely fit the length-age relationship of cohorts of a variety of species (e.g., Kappenman 1981, Kauffmann 1981, Tanabe 1988, Smith et al. 1997). The success of individual- and cohort-based growth models, such as the von Bertalanffy model, however, suggests that a few mathematical relationships might also describe the length-age relationships of populations. This study provides an example of the development of such a general relationship for hard clam populations.

Defining a general mathematical relationship that describes the age-length distributions allows development of age-length keys from fewer age-length measurements and application of age-length models. Moreover, population-to-population differences in the parameterization of the age-length model may be illustrative of important ecological and population dynamics processes determining the structure of the population just as variations in the parameters used in a von Bertalanffy growth model reflect differences in the structure of a cohort (e.g., Kornobis 1977, McCuaig \& Green 1983, Nix et al. 1995).

\section{Implications of a Generalized Age-length Relationship}

The earlier mentioned analyses suggest that a twisted bivariate Gaussian function can successfully describe age-length distributions that are produced by modifications in hard clam population dynamics, including changes in growth rate, mortality rate, recruitment rate and cohort genotypic composition. The age-length characteristics of populations have not been fully investigated since the initial development of a theoretical growth model (Pütter 1920, von Bertalanffy 1938) in spite of numerous experimental and theoretical studies at the cohort level. Thus, the extent to which the present formulation can be extended to other shellfish and nonshellfish taxa remains unclear. The robustness of the formulation described by the twisted bivariate Gaussian may have general application for producing age-length distributions.

The different population processes that were used to produce the simulated age-length data sets used to test the twisted bivariate Gaussian yielded a unique set of parameter values that defined the angle of the long axis, the degree of curvature, the length of the relation along the twisted $x$ axis, and the tendency for the $y$ axis to spread asymmetrically about $x$ (Table 4). These characteristics of the age-length distribution are controlled by the growth rates, the form of and degree of mortality imposed on the population, the stability of recruitment, and the inherent genetic composition of the recruits. These parameters provide information concerning the processes controlling the structuring of the population in much the same way as values of growth parameters (e.g., the von Bertalanffy $k$ and $L_{\infty}$ ) provide information on the processes controlling cohort growth. The extent to which the specific values of the parameters might be predictive of certain combinations of population dynamics cannot yet be determined, but the simulations presented here are encouraging of such an outcome. Obtaining a set of ages and lengths and then fitting the twisted bivariate Gaussian to these data, could potentially provide more insight into population processes than may be obtained from mul- tiyear studies of the suite of complex population dynamicsdetermining processes that produce observed age-frequency distributions.

Measurements of length are easy to obtain, but age is the more often desired quantity and conversion of the one into the other requires age-length keys, which are time consuming to construct. As a result, more is known about length frequencies in natural populations than about the complementary age frequencies. The cost and time of obtaining age-length keys directly limit their use in fisheries management and in ecological investigation. As a consequence, little is known about how age-length properties of populations might change within metapopulations, along environmental gradients, or in response to long-term climate changes. For longlived animals such as hard clams, the latter is particularly important.

Generating an age-length key requires information from many individuals of differing ages for a given length and many individuals of differing lengths for a given age (Fig. 27). Because the age-length distributions twist along the length axis and spreads asymmetrically, the age-length array must be filled over all lengths and ages. As a result, a simple statistical function will not have the flexibility to describe the variation in age with length or in length with age over all ages and lengths. For example, a simple Gaussian function will accumulate increasing error as age and length increase. In the larger length classes and older age classes, the increased rarity of the animals themselves imposes an additional constraint on the function used to describe age-length distributions. As a consequence, filling age-length key arrays with sufficient replicate measurements to describe the underlying statistical distributions is difficult.

The availability of a single mathematical formulation to describe age-length distributions for hard clam populations provides a significant advance in the ability to generate age-length keys. Many fewer individual age-length measurements are necessary, provided they are adequate representations of the population, to describe the age-length distribution. A sparser data set might be used to determine parameter values for the general mathematical formulation that then can be used to fill in the full age-length distribution needed for a key. The density of the data over the age-length spectrum of the population needed to do this requires further investigation, but tests done with the simulated age-length data sets produced in this study suggest that age-length keys could be created with tens rather than hundreds of age-length measurements. Should this prove to be the case, then the existence of a general mathematical formulation provides opportunity to investigate how age and length independently determine population structure beyond what has heretofore been possible to achieve. Furthermore, the twisted bivariate Gaussian expands the theoretical formulations defining the age-length character of the cohort into that of the population by identifying parameters analogous to the rate of length increase $(k)$ and maximum length $\left(L_{\infty}\right)$ in the von Bertalanffy model (von Bertalanffy 1938, Fabens 1965, Kimura 1980). These parameters can now serve as the basis for theoretical models of population age-length compositions because they are determined by individual growth and mortality rates, but also by population-dependent processes, compensatory and otherwise.

\section{ACKNOWLEDGMENTS}

This research was supported by New York Sea Grant project numbers NA96FL0279 and NA16FL2699. Computer resources and facilities were provided by the Center for Coastal Physical Oceanography at Old Dominion University. 


\section{LITERATURE CITED}

Ansell, A. D. 1968. The rate of growth of the hard clam Mercenaria mercenaria (L) throughout the geographical range. J. Cons. Perm. int. Explor. Mer. 31:364-409.

Bayne, B. L., P. N. Salkeld \& C. M. Worrall. 1983. Reproductive effort and value in different populations of the marine mussel, Mytilus edulis L. Oecologia 59:18-26.

Boulding, E. G. \& T. K. Hay. 1984. Crab response to prey density can result in density-dependent mortality of clams. Can. J. Fish. Aquat. Sci. 41:521-525.

Bradbury, A. \& J. V. Tagart. 2000. Modeling geoduck, Panopea abrupta (Conrad, 1849) population dynamics II. Natural mortality and equilibrium yield. J. Shellfish Res. 19:63-70.

Bricelj, V. M. 1979. Fecundity and related aspects of hard clam (Mercenaria mercenaria reproduction in Great South Bay, New York. M.S. Thesis, State University of New York at Stony Brook. 98 pp.

Bricelj, V. M. 2000. Perspectives on possible factors influencing the abundance of hard clams. In: C. G. Schlenk, editor. Rough transcript of the Workshop on Hard Clam Population Dynamics. Research priorities for the south shore of Long Island. New York Sea Grant. 94 pages and appendices.

Bricelj, V. M. \& R. E. Malouf. 1980. Aspects of reproduction of hard clams Mercenaria mercenaria in Great South Bay, New York. Proc. Natl. Shellfish Assoc. 70:216-229.

Bricelj, V. M. \& R. E. Malouf. 1984. Influence of algal and suspended sediment concentrations on the feeding and physiology of the hard clam Mercenaria mercenaria. Mar. Biol. 84:155-165.

Bricelj, V. M., R. E. Malouf \& C. de Quillfeldt. 1984. Growth of juvenile Mercenaria mercenaria and the effect of resuspended bottom sediments. Mar. Biol. 84:167-173.

Brown, J. H., P. A. Marquet \& M. L. Taper. 1993. Evolution of body size: consequences of an energetic definition of fitness. Am. Nat. 142:573584.

Buckner, S. C. 1984. Aspects of the population dynamics of the hard clam, Mercenaria mercenaria L., in Great South Bay, New York. Ph.D. dissertation, State University of New York at Stony Brook, NY. 217 pp.

Carpenter, M. H. \& C. A. Kennedy. 1994. Fourth-Order 2N-Storage Runge-Kutta Schemes, NASA Technical Memorandum 109112.

Cerrato, R. 2000a. Perspectives on possible factors influencing the abundance of hard clams. In: C. G. Schlenk, editor. Rough Transcript of the Workshop on Hard Clam Population Dynamics. Research priorities for the south shore of Long Island. New York Sea Grant. 94 pages and appendices.

Cerrato, R. M. 2000b. What fish biologists should know about bivalve shells. Fish. Res. 46:39-49.

Clark, W. G. 1999. Effects of an erroneous natural mortality rate on a simple age-structured stock assessment. Can. J. Fish. Aquat. Sci. 56: 1721-1731.

Connell, J. H. \& W. P. Sousa. 1983. On the evidence needed to judge ecological stability or persistence. Am. Nat. 121:789-824.

COSMA (Coastal Ocean Science and Management Alternatives Program). 1985. Suffolk County's Hard Clam Industry. Chapters 1-11 plus appendices.

Craig, G. \& G. Oertel. 1966. Deterministic models of living and fossil populations of animals. Geol. Soc. Lond. 122:315-355.

Davis, H. C. \& P. E. Chanley. 1956. Spawning and egg production of oysters and clams. Biol. Bull. 110:117-128.

Dennison, W. C., L. E. Koppelman \& R. Nuzzi. 1991. Chapter 4. Water quality. pp. 23-31, In: J. R. Shubel, T. M. Bell \& H. H. Carter. The Great South Bay. Albany: State University of New York Press. 107 pp.

Devillers, N., A. G. Eversole \& J. J. Isely. 1998. A comparison of four growth models for evaluating growth of the northern quahog Mercenaria mercenaria (L.). J. Shellfish Res. 17:191-194.

Doering, P. H. \& C. A. Oviatt. 1986. Application of filtration rate models to field populations of bivalves: An assessment using experimental mesocosms. Mar. Ecol. Prog. Ser. 31:265-275.

Engle, J. B. \& C. R. Chapman. 1953. Oyster condition affected by attached mussels. Natl Shellfish. Assoc. Conv. Add. for 1951. pp. 70-78.

Eversole, A. G. 2000. Reproduction in Mercenaria mercenaria. In: J. N. Kraeuter \& M. Castagna, editors. Biology of the hard clam. Amsterdam: Elsevier Science. pp. 221-260.

Evjen, A. J. 1985. Above bottom bivalve growth in Long Island Sound and the influence of resuspended sediment. M.S. Thesis, State University of New York at Stony Brook. 83 pp.

Fabens, A. J. 1965. Properties and fitting of the von Bertalanffy growth curve. Growth 29:265-289.

Frechette, M. \& D. Lefaivre. 1990. Discriminating between food and space limitation in benthic suspension feeders using self-thinning relationships. Mar. Ecol. Prog. Ser. 65:15-23.

Goodwin, D. H., K. W. Flessa, B. R. Schöne \& D. L. Dettman. 2001. Cross-calibration of daily growth increments, stable isotope variation, and temperature in the Gulf of California bivalve mollusk Chione cortezi: implications for paleoenvironmental analysis. Palaios 16:387398.

Grizzle, R. E. 1988. The relative effects of tidal currents, seston and bottom sedimentation on individual growth of Mercenaria mercenaria (Linné): feeding ecology and aquacultural implications. Ph.D. Dissertation, Rutgers University, New Brunswick, NJ. 293 pp.

Grizzle, R. E., V. M. Bricelj \& S. E. Shumway. 2000. Physiological ecology of Mercenaria mercenaria. In: J. N. Kraeuter \& M. Castagna, editors. Biology of the hard clam. Amsterdam: Elsevier Science. pp. 305-382.

Hamwi, A. 1969. Oxygen consumption and pumping rate of the hard clam Mercenaria mercenaria L. Ph.D. Dissertation, Rutgers University, New Brunswick, NJ. 177 pp.

Hawkins, A. J. S. \& B. L. Bayne. 1992. Physiological interrelations and the regulation of production. In: E. Gosling, editor. The mussel Mytilus: ecology, physiology, genetics, and culture. Amsterdam: Elsevier. pp. 171-222.

Hibbert, C. J. 1977. Growth and survivorship in a tidal-flat population of the bivalve Mercenaria mercenaria from Southampton water. Mar. Biol. 44:71-76.

Hilborn, R. \& C. J. Walters. 1992. Quantitative fisheries stock assessment: Choice, dynamics and uncertainty. New York: Chapman \& Hall. 570 pp.

Hoenig, J. M. 1983. Empirical use of longevity data to estimate mortality rates. Fish. Bull. (Wash. D. C.) 82:898-903.

Honkoop, P. J. C. \& B. L. Bayne. 2002. Stocking density and growth of the Pacific oyster (Crassostrea gigas) and the Sydney rock oyster (Saccostrea glomerata) in Port Stephens, Australia. Aquaculture 213:171186.

Hughes, R. N. 1980. Optimal foraging theory in the marine context. Oceanogr. Mar. Biol. Аnпи. Rev. 18:423-481.

Hunt, J. H., W. G. Ambrose, Jr. \& C. H. Peterson. 1987. Effects of the gastropod, Ilyanassa obsoleta (Say) and the bivalve, Mercenaria mercenaria (L.), on larval settlement and juvenile recruitment of infauna. J. Exp. Mar. Biol. Ecol. 108:229-240.

Hyun, K.-H., I.-C. Pang, J. M. Klinck, K.-S. Choi, J.-B. Lee, E. N. Powell, E. E. Hofmann \& E. A. Bochenek. 2001. The effect of food composition on Pacific oyster Crassostrea gigas (Thunberg) growth in Korea: a modeling study. Aquaculture 199:41-62.

Kappenman, R. F. 1981. A method for growth curve comparisons. Fish. Bull. (Wash. D. C.) 79:95-101.

Kassner, J. \& R. E. Malouf. 1982. An evaluation of "spawners transplants" as a management tool in Long Island's hard clam fishery. J. Shellfish Res. 2:165-172.

Kauffmann, K. W. 1981. Fitting and using growth curves. Oecologia 49: 293-299.

Kennish, M. J. 1978. Effects of thermal discharges on mortality of Mer- 
cenaria mercenaria in Barnegat Bay, New Jersey. Environ. Geol. 2: 223-254.

Kennish, M. J. \& R. E. Loveland. 1980. Growth models of the northern quahog, Mercenaria mercenaria (Linné). Proc. Natl. Shellfish Assoc. 70:230-239.

Kimura, D. K. 1977. Statistical assessment of the age-length key. J. Fish. Res. Board Canada 34:317-324.

Kimura, D. K. 1980. Likelihood methods for the von Bertalanffy growth curve. Fish. Bull. (Wash. D.C.) 77:765-776.

Kobayashi, M., E. E. Hofmann, E. N. Powell, J. M. Klinck \& K. Kusaka. 1997. A population dynamics model for the Japanese oyster, Crassostrea gigas. Aquaculture 149:285-321.

Kornobis, S. 1977. Ecology of Dreissena polymorpha (Pall.) (Dreissenidae, Bivalvia) in lakes receiving leaded water discharges. Pol. Arch. Hydrobiol. 24:531-545.

Kraeuter, J. N., S. Buckner \& E. N. Powell. 2005. A note on a spawnerrecruit relationship for a heavily exploited bivalve: the case of northern quahogs (hard clams), Mercenaria mercenaria in Great South Bay, New York. J. Shellfish Res. 24:1043-1052.

Lika, K. \& R. M. Nisbet. 2000. A dynamic energy budget model based on partitioning of net production. J. Math. Biol. 41:361-386.

Lipinski, M. R., M. D. Durholtz \& L. G. Underhill. 1998. Field validation of age readings from the statoliths of chokka squid (Loligo vulgaris reynaudii d'Orgibny, 1845) and an assessment of associated errors. ICES J. Mar. Sci. 55:240-257.

Loesch, J. G. \& D. S. Haven. 1973. Estimated growth functions and sizeage relationships of the hard clam, Mercenaria mercenaria, in the York River, Virginia. Veliger 16:76-81.

Lundberg, S. \& L. Persson. 1993. Optimal body size and resource density. J. Theor. Biol. 164(2):163-181.

Malinowski, S. M. 1985. The population ecology of the hard clam, Mercenaria mercenaria, in eastern Long Island. Ph.D. dissertation, University of Connecticut. $101 \mathrm{pp}$.

Malouf, R. E. 1991. The hard clam: its biology and the natural processes that affect it success. In: J. R. Schubel, T. M. Bell \& H. H. Carter, editors. The Great South Bay. Albany, NY: State University of New York Press. pp. 43-54.

McCuaig, J. M. \& R. H. Green. 1983. Unionid growth curves derived from annual rings: a baseline model for Long Point Bay, Lake Erie. Can. J. Fish. Aquat. Sci. 40:436-442.

McNamara, J. M. 1993. State-dependent life-history equations. Acta Biotheor. 41:165-174.

Millstein, J. \& C. E. O'Clair. 2001. Comparison of age-length and growthincrement general growth models of the Schnute type in the Pacific blue mussel, Mytilus trossulus (Gould). J. Exp. Mar. Biol. Ecol. 262: 155-176.

Mohn, R. 2001. A comparison of three methods to convert catch at length data into catch at age. Int. Comm. Conserv. Atl. Tuna 42:110-119.

Murphy, R. C. 1985. Factors affecting the distribution of the introduced bivalve, Mercenaria mercenaria, in a California lagoon-The importance of bioturbation. J. Mar. Res. 43:673-692.

Nix, E. R., C. R. Fisher, J. Vodenichar \& K. M. Scott. 1995. Physiological ecology of a mussel with methanotrophic endosymbionts at three hydrocarbon seep sites in the Gulf of Mexico. Mar. Biol. (Berl.) 122: 605-617.

Nixon, S. W., S. Granger, B. A. Buckley, M. Lamont \& B. Rowell. 2004. $\mathrm{A}$ one hundred and seventeen year coastal water temperature record from Woods Hole, Massachusetts. Estuaries 27:397-404.

Nunney, L. \& D. R. Elam. 1994. Estimating the effective population size of conserved populations. Conserv. Biol. 8:175-184.
Patterson, K. R. 1998. Assessing fish stocks when catches are misreported: Model, simulation tests, application to cod, haddock, and whiting in the ICES area. ICES J. Mar. Sci. 55:878-891.

Peterson, C. H., P. B. Duncan, H. C. Summerson \& G. W. Safrit, Jr. 1983. A mark-recapture test of annual periodicity of internal growth band deposition in shells of hard clams, Mercenaria mercenaria, from a population along the southeastern United States. Fish. Bull. (Wash. D.C.) $81: 765-779$.

Peterson, C. H., H. C. Summerson \& J. Huber. 1995. Replenishment of hard clam stocks using hatchery seed: Combined importance of bottom type, seed size, planting season, and density. J. Shellfish Res. 14:293300.

Powell, E. N. \& R. J. Stanton, Jr. 1985. Estimating biomass and energy flow of molluscs in palaeo-communities. Palaeontology (Lond.) 28:134

Powell, E. N., S. E. King \& A. J. Bonner. 2005. Determination of temporal trends in size in vessel-based reporting in the USA Illex illecebrosus fishery. J. Appl. Ichthyol. 21:184-197.

Press, W. H., B. P. Flannery, S. A. Teukolsky \& W. T. Vetterling. 1989. Numerical recipes. Cambridge: Cambridge University Press. 702 pp.

Pütter, A. 1920. Studien über physiologische Ähnlichkeit VI. Wachstumsähnlichkeiten. Pflügers Arch. ges. Physiol. 180:298-340.

Quaglietta, C. E. 1987. Predation by Mnemiopsis leidgi on hard clam larvae and other natural zooplankton in Great South Bay, New York. M.S. Thesis, State University of New York at Stony Brook. 66 pp.

Richardson, C. A. 2001. Molluses as archives of environmental change. Oceanogr. Mar. Biol. Annu. Rev. 39:103-164.

Smith, E. B., F. M. Williams \& C. R. Fisher. 1997. Effects of intrapopulation variability on von Bertalanffy growth parameter estimates from equal mark-recapture intervals. Can. J. Fish. Aquat. Sci. 54:2025-2032.

Schlenk, C. G. (ed.). 2000. Transcript of the Workshop on Hard Clam Population Dynamics. Port Jefferson, New York, New York Sea Grant. $22 \mathrm{pp}$.

Soniat, T. M., E. N. Powell, E. E. Hofmann \& J. M. Klinck. 1998. Understanding the success and failure of oyster populations: The importance of sampled variables and sample timing. J. Shellfish Res. 17: $1149-1165$.

Soniat, T. M. \& S. M. Ray. 1985. Relationships between possible available food and the composition, condition, and reproductive state of oysters from Galveston Bay, Texas. Contrib. Mar. Sci. 28:109-121.

Soniat, T. M., S. M. Ray \& L. M. Jeffrey. 1984. Components of the seston and possible available food for oysters in Galveston Bay, Texas. Contrib. Mar. Sci. 27:127-141.

Tanabe, K. 1988. Age and growth rate determinations of an intertidal bivalve, Phacosoma japonicum, using internal shell increments. Lethaia 21:231-241.

Thompson, R. J. \& B. L. Bayne. 1974. Some relationships between growth, metabolism and food in the mussel Mytilus edulis. Mar. Biol. 27:317326.

von Bertalanffy, L. 1938. A quantitative theory of organic growth (inquiries on growth laws. II.). Hum. Biol. 10:181-213.

Walker, R. L. 1983. Population dynamics of the hard clam, Mercenaria mercenaria (Linné), and its relation to the Georgia hard clam fishery. M.S. Thesis Georgia Inst. Tech., 121 pp.

Wallace, H. V. E. 1991. A comparison of hard clam population characteristics between high and low density regions within Great South Bay. M.S. Thesis, State University of New York at Stony Brook, $67 \mathrm{pp}$.

Willows, R. I. 1992. Optimal digestive investment: a model for filterfeeders experiencing variable diets. Limnol. Oceanogr. 37:829-847. 